JOINT TRANSPORTATION RESEARCH PROGRAM

FHWA/IN/JTRP-2007/3

Final Report

SYNTHESIS STUDY: HEAT TREATMENT AND ITS EFFECTS ON REHABILITATING STEEL BRIDGES IN INDIANA

Matthew Lackowski

Amit Varma

April 2007 
Final Report

FHWA/IN/JTRP-2007/3

\title{
SYNTHESIS STUDY: HEAT TREATMENT AND ITS EFFECTS ON REHABILITATING STEEL BRIDGES IN INDIANA
}

\author{
By \\ Matthew Lackowski \\ Graduate Research Assistant \\ and \\ Amit Varma \\ Assistant Professor \\ School of Civil Engineering \\ Purdue University \\ Joint Transportation Research Program \\ Project No. C-36-56EEEE \\ File No. 7-4-82 \\ SPR-3025 \\ Conducted in Cooperation with the \\ Indiana Department of Transportation and the \\ U.S. Department of Transportation \\ Federal Highway Administration
}

The contents of this report reflect the views of the authors, who are responsible for the facts and the accuracy of the data presented herein. The contents do not necessarily reflect the official view or policies of the Indiana Department of Transportation or the Federal Highway Administration at the time of publication. The report does not constitute a standard, specification, or regulation.

Purdue University

West Lafayette, Indiana

April 2007 


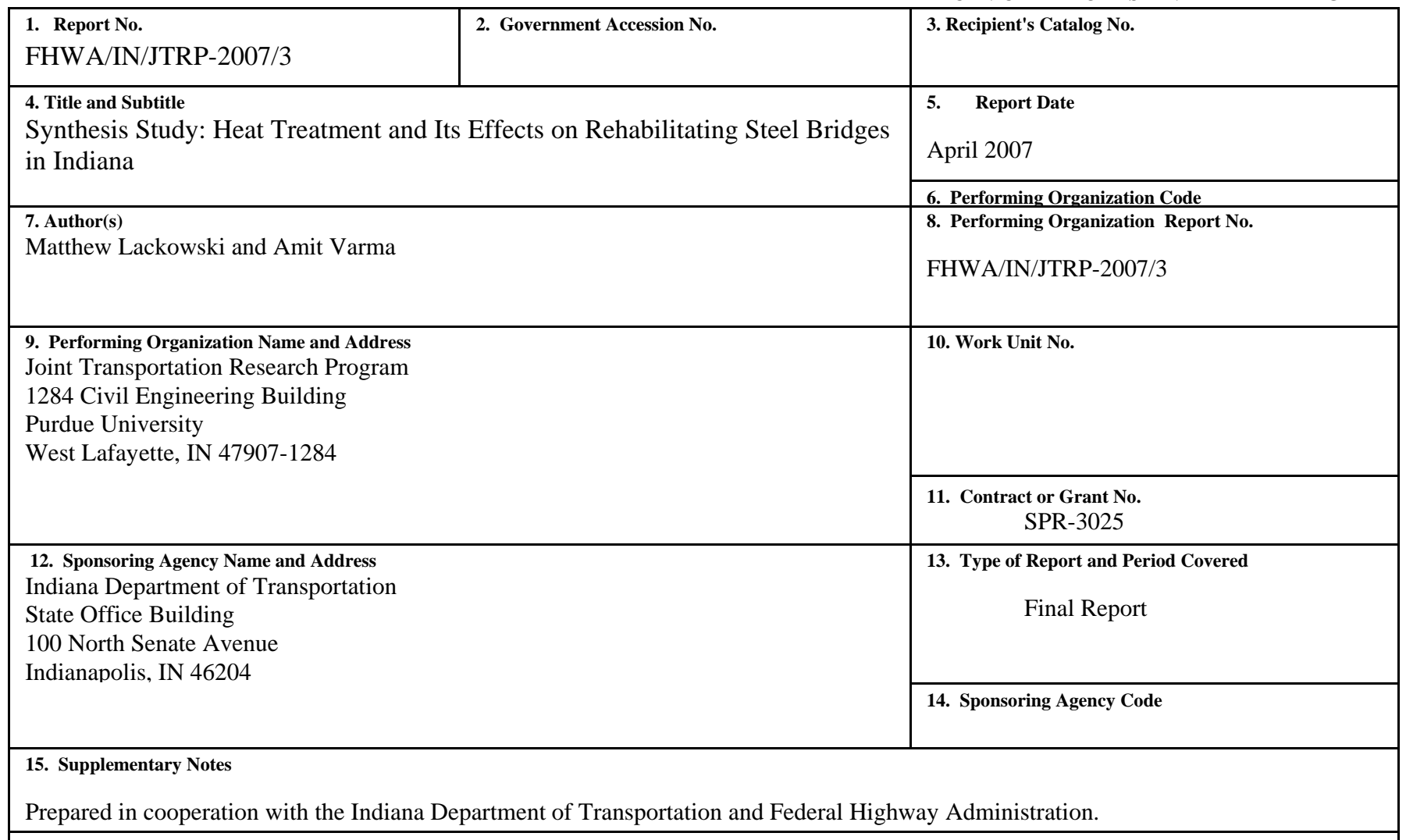

\section{Abstract}

The literature review of prior heat straightening research indicated that significant research has been conducted on the development of: (i) heat straightening repair techniques and their field implementation, (ii) guidelines and recommendations for heat straightening repair, (iii) empirical procedures for estimating plastic rotations achieved during heat straightening, (iv) empirical procedures for predicting residual stresses caused by heat straightening, and (v) the effects of heat straightening on the structural properties of repaired bridges. Currently, there is a need for additional research on: (a) the fatigue performance of heat straightened beams, (ii) the effects of single and multiple heat straightening on the fracture toughness and microstructure of steel beams, (iii) the development of guidelines for evaluating and replacing steel beams subjected to single or multiple damage-repairs, and (iv) investigating the effects of realistic heat straightening with imperfections on the properties and serviceability of steel beam bridges.

The literature review of existing heat treatments indicates that heat straightening with maximum temperature limited to $1200^{\circ} \mathrm{F}$ is relatively similar to the process annealing heat treatment. Heat straightening with maximum temperature limited to $1400^{\circ} \mathrm{F}$ is similar to the normalizing annealing heat treatment. Both these heat treatments repair plastically deformed microstructure by the phenomenon known as recovery and recrystallization. Normalizing annealing is more efficient and faster than process annealing in repairing the plastically deformed microstructure by recrystallization. Heat treatment and repair of the material microstructure is incidental to the heat straightening repair process. The heat straightened beam can be further heat treated to complete the repair of the material microstructure (recrystallization etc.). The practical and economic feasibility of additional heat treatment using electrically powered and controlled radiant heaters was evaluated and found to be reasonable.

\section{Key Words}

18. Distribution Statement

Heat straightening, heat treatment, thermal, repair, rehabilitation, retrofit, steel, bridges, damage, impact.

No restrictions. This document is available to the public through the National Technical Information Service, Springfield, VA 22161

\section{Security Classif. (of this report) Unclassified}

\author{
20. Security Classif. (of this page) \\ Unclassified
}

20. Security Classif. (of this page)
Unclassified

Form DOT F 1700.7 (8-69) 


\section{Table of Contents}

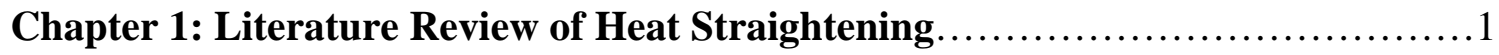

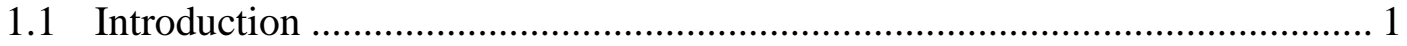

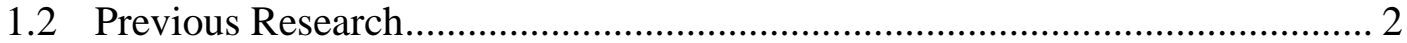

1.2.1 Historical Research ............................................................................... 2

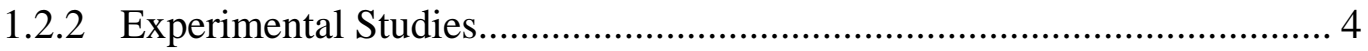

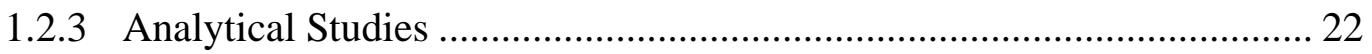

1.2.4 Full-Scale Studies............................................................................ 26

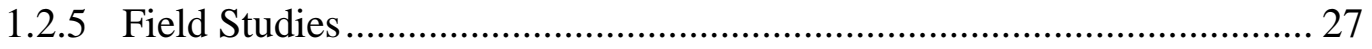

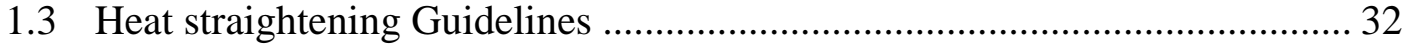

1.4 Conclusions from Literature Review ............................................................ 36

Chapter 2: Literature Review of Heat Treatment ............................. 36

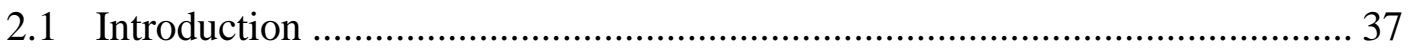

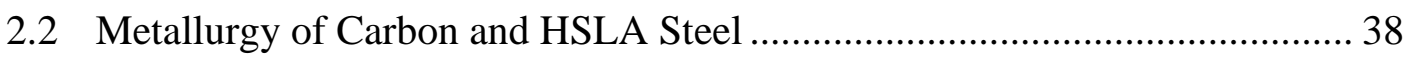

2.3 Isothermal and Continuous Cooling Transformations................................. 43

2.4 Effects of Plastic Deformation on Steel Microstructure ................................ 46

2.5 Heat Treatments of Steel and their Relation to Heat Straightening .............. 47

2.6 Recovery, Recrystallization, and Grain Growth....................................... 51

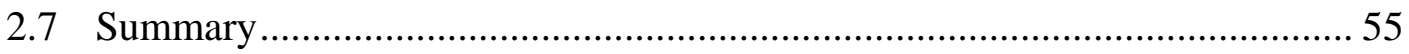

Chapter 3: Survey of Heat Straightening Companies .............................57

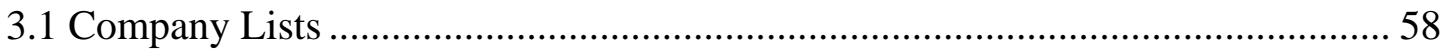

3.2 Survey Form Submitted To Companies............................................................. 58

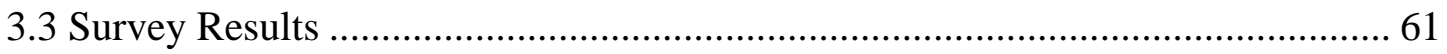

Chapter 4: Heat Treatment Feasibility Analysis ...........................62

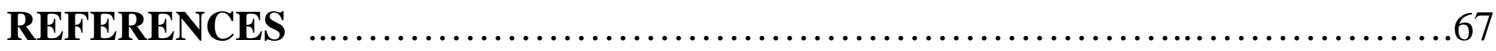




\section{Chapter 1 Literature Review of Heat Straightening}

\subsection{INTRODUCTION}

An extensive literature review of prior heat straightening experimental and analytical investigations as well as current provisions for heat straightening repair are provided in this section. Previous research on heat straightening damaged steel bridges has addressed the following issues in some detail:

- Heat straightening repair techniques for damaged steel members by Weerth (1971), Horton (1973), Roeder (1985), Avent and Fadous (1998) and Avent et al. (1992) among others

- Effects of heat straightening on the structural properties of steel by Pattee et al. (1970), Nicholls and Weerth (1972), Avent et al. (1992), and Till (1996) among others

- Development of design guidelines and recommendations for heat straightening by Shanafelt and Horn (1984), Avent (1992), Avent and Mukai (1998), and FHWA (1998)

Section 1.2 of this report provides a summary review of the previous research conducted on heat straightening. Section 1.2.1 presents some of earliest (historical) research on heat straightening in the United States. Section 1.2.2 focuses on experimental research on heat straightening steel plates and beams in the laboratory. Section 1.2.3 presents some of the analytical research on heat straightening. Section 1.2.4 presents a summary and review of the large-scale field studies on heat straightening damaged steel bridges. Section 1.3 presents some of the current heat straightening provisions and guidelines recommended by FHWA (1998) and various state departments of transportation (DOTs). Section 1.4 summarizes the major findings and conclusions from the literature review and identifies gaps in the knowledge of the effects of heat straightening on the structural properties of steel beam bridges. 


\subsection{PREVIOUS RESEARCH}

A summary review of previous heat straightening research is presented in this section. In general, prior heat straightening research has addressed the following objectives:

- Understanding the thermo-plastic deformation process

- Determining the heating parameters that have the greatest impact on and benefit plastic deformations

- Calculating the residual stress magnitudes and distributions induced by heat straightening

- Developing analytical models for plastic rotation and residual stress patterns aided with experimental data

- Determining the detrimental effects of heat straightening on the structural properties of steel

- Investigating the effects of multiple damage-heat straightening repairs on steel members

- Developing practical guidelines for implementation of heat straightening in the field

Three comprehensive studies have been conducted to summarize prior experimental data and knowledge and to provide guidelines for practitioners (Shanafelt and Horn 1984, Avent and Fadeous 1988, Avent et al. 1992). The two latter studies have provided substantial scientific data from experimental and analytical studies to support recommendations for damage assessment, optimization of heat straightening techniques, and development of heat straightening repair procedures.

\subsubsection{Historical Research}

This section presents a summary of some of the earliest research involving heat straightening damaged steel members. These initial studies focused on developing a better understanding of the thermal stresses, plastic deformations, and practical applications of heat straightening. 
Fabricators have employed thermal stresses for dimensional modifications since the 1930's (Roeder 1986). These stresses have typically been used to camber and sweep steel bridge beams, but more recently to repair damaged bridge beams. Bridge beams are usually damaged as a result of over-height trucks, fire, wind, earthquake, blast, mishandling, out-of-control vehicles, and over-loading. Early heat straightening repairs were performed with insufficient scientific rationale. Hence, early research studies were focused on understanding the thermal expansion and contraction properties of the steel (Holt 1955, Ditman 1961, For Chin 1962)and general procedures for applications (Holt 1965).

In 1938, J. Holt wrote one of the first technical papers on heat straightening. Holt (1938) addressed the power of thermal contraction and its effectiveness in dimensional modification of structural steel members and procedures for heat straightening steel members damaged to various configurations. This paper was revised and published in 1955 (Holt 1955). Additions to the revised paper include various applications for heat straightening repairs, detailed examples for implementing heat straightening, and the role and effect that restraining forces have on plastic rotations during the heat straightening process.

R. Holt published three papers on the subject of heat straightening that provided practitioners with heat straightening guidelines. In his first paper, R. Holt (1965) addresses procedures for applying a Vee heat pattern and the importance of not retracing the serpentine path of the Vee heat pattern as the prior heated material is providing the necessary confinement. R. Holt (1965) also addresses how the steel can be monitored by visual inspection. At about $1200{ }^{\circ} \mathrm{F}$, the steel appears a dull red. The steel color appears satin silver with a shade four welding lens.

In his second paper, R. Holt (1971) addresses the effects of external restraints as well as the application of different heating patterns such as the line heat, the spot heat, the strip heat, and the Vee heat. R. Holt (1971) emphasizes that external restraints are a combination of applied jacking forces and dead loads resulting from members such as diaphragms. Attached members can restrain plastic rotation of the heated steel member under certain conditions. External jacking forces should always be applied before heating 
the member. In his third paper, R. Holt (1977) addresses the local buckling of steel members and relates local buckling to the width of the heating pattern.

\subsubsection{Experimental Studies}

Five major experimental studies have been conducted on the heat-straightening repair of steel bridges. These studies have focused on the deformations of heat straightened specimens (plastic rotations), residual stresses induced from heat straightening, and structural properties of heat straightened steel.

\subsubsection{Plastic Rotations}

Plastic rotation is defined as the angular change of the intersection of the tangents extended from opposite sides of the damaged area. Initial experimental studies focused on evaluating the plastic rotations associated with heat curving undamaged steel plates and wide flange sections utilizing an edge-heating pattern (Brockenbrough and Ives 1970, Brockenbrough 1970, Horton 1973). This heating pattern is typically used to introduce a smooth curvature (sweep) in bridge girders. The resulting plastic deformation occurs primarily within the heated area of the specimen (Nichols and Weerth 1972). The fundamental heating pattern for heat straightening is the Vee heat that produces a small but sharp curvature at the location of the heat. Vee heats are used to induce both strong and weak axis bending in beams. Researchers have investigated this heating pattern with variations of different heating parameters. The following parameters have been considered by previous experimental studies; (a) initial yield stress, (b) heating temperature, (c) heating time, (d) heating sequence and pattern, (e) Vee angle (f) Vee depth, (g) geometric shape and size, (h) external restraining forces, (i) internal restraining forces, and (j) quenching.

Weerth (1971) performed the earliest experimental research on the application of Vee heats to initially straight (undamaged) steel plates. The objective of the experimental research was to evaluate the behavior of steel plates subjected to the Vee heat pattern with variations in the Vee angle and the depth of the Vee. Three A36 grade steel plates 6 in. wide by $3 / 8$ in. thick were subjected to a total of 21 Vee heats. The Vees were applied to only one side of the plate and the Vee depth ratios were held constant for each plate. 
The temperature of the specimens was monitored using thermal sticks. The experimental program consisted of variations of the Vee angle $\left(24^{\circ}, 30^{\circ}, 36^{\circ}, 42^{\circ}, 48^{\circ}, 54^{\circ}\right.$, and $\left.60^{\circ}\right)$, and the depth of the Vee in respect to the base width of the flange $(1 / 2,3 / 4$, and 1$)$. A maximum heating temperature of $1200{ }^{\circ} \mathrm{F}$ was enforced. Restraining forces of $490 \mathrm{lb}$. were applied prior to the application of the Vee heat. The results from this study revealed that plastic rotation is directly proportional to the angle of the Vee heat and full-depth Vee heats and restraining forces positively influence the plastic rotation of the heated specimen.

Horton (1973) performed the earliest experimental research on the application of Vee heats to initially straight (undamaged) steel wide flange sections. The objective of this experimental research was similar to Weerth's (1971) study except that it was conducted on wide flange sections. The objective was to evaluate the behavior of the wide-flange sections subjected to Vee heating patterns with variations in the Vee angle and the Vee depth. Sixty individual Vee heats were conducted on ten W6 x 15.5, four W8 x 10, and four W10 x 33 sections made from hot rolled A36 steel. Five heating sequences were used to produce full and partial sweep and cambering movements in the specimens. All sections were supported as cantilevers with a dead load attached at the end of the beam prior to Vee heating. This load produced a bending stress of $9.0 \mathrm{ksi}$ at the extreme fibers of the heated zone for all specimens. The temperature of the specimens was monitored using thermal indicator sticks. The experimental program consisted of variations of the Vee angles $\left(30^{\circ}, 40^{\circ}\right.$, and $\left.50^{\circ}\right)$ and depth ratios of full-depth or half-depth in respect to the base width. A maximum heating temperature of $1200{ }^{\circ} \mathrm{F}$ was enforced. The specimens were cooled using one of three methods; (1) convection, (2) immediate atomized water spray, or (3) delayed atomized water spray. Results from this study revealed the following conclusions:

- Significant increases in the plastic rotation occur when a full-depth Vee heat is applied in comparison to half-depth Vee heat

- The study indicates that the relationship between plastic rotation and Vee angle is fairly linear 
- Effective heating sequences and patterns for wide flange sections were revealed in this study

- Water mist cooling was insignificant in increasing the plastic rotation in the heated specimens. It merely hastened the application of subsequent heats

Roeder (1985 and 1986) and experimentally investigated the application of Vee and strip heats to initially straight (undamaged) steel plates and wide flange sections. The objective of this study was to improve the understanding of the thermal or heat straightening process for seismic damage-repair. The experimental study consisted of three series of individually heated test specimens. Series A consisted of sixty-eight plate specimens subjected to Vee heating patterns. Series B1 consisted of eight axially loaded wide flange sections subjected to Vee heating patterns. Series B2 consisted of two simply supported wide flange sections subjected to strip heating patterns. The following heating parameters were varied throughout the study; (a) heating temperature, (b) heating time, (c) geometric size, (d) geometric shape, (e) geometry of heating pattern, (f) initial yield strength, (g) external restraining forces, (h) internal restraining forces, and (i) quenching. Emphasis was placed on obtaining the exact temperature of the heated specimens. Therefore, temperature monitoring devices such as an Omega non-contact pyrometer, thermocouples, and temperature indicating crayons were used throughout the experiments. Deflections were measured using linear voltage displacement transducers (LVDTs). Strain gauges provided a measure of the time and temperature dependent forces and moments in the column specimens. A 10 in. Whittemore Gage was used to measure the strains at specified locations in the beam specimens. The experimental program consisted of the following details and variations of the heating parameters:

- Series A consisted of fifty-nine plates made of A36 (36 ksi) grade steel and nine plates made of A514 (100 ksi) grade steel. Sixty of the plates were 3/8 in. by 6 in., four of the plates were $1 / 4 \mathrm{in}$. by 8 in., and four of the plates were 3/4 in. by 6 in. Thirteen plates were quenched prior to the experiments. The Vee angles were $45^{\circ}$, $60^{\circ}$, or $82^{\circ}$. The depth ratio was either $3 / 4$ or 1 times the width of the plate. In some cases, restraining forces were applied at midspan causing a restraining moment equal 
to $25 \%$ of the plastic moment capacity $\left(M_{p}\right)$ at midspan where the Vee heat was applied. Maximum heating temperatures varied from $800^{\circ} \mathrm{F}$ to $1600^{\circ} \mathrm{F}$.

- Series B1 consisted of eight wide flange sections (W6x25) made from A36 grade steel. Vee heats were applied to a single flange at a depth of 2/3 times the base width and at Vee angles of $45^{\circ}, 60^{\circ}$, and $82^{\circ}$. All sections were simply supported for weak axis buckling. Compressive loads were applied on six specimens from $40 \%$ to $80 \%$ of AISC design service load. The other two specimens were not subjected to compressive loads. $\mathrm{Kl} / \mathrm{r}$ ratios ranged from 60 to 120. A maximum heating temperature of $1200^{\circ} \mathrm{F}$ was applied to all columns.

- Series B2 consisted of two wide flange sections (W12x14) made from A36 grade steel. The beam specimens were simply supported at $7 \mathrm{ft}$. and subjected to continuous strip heating patterns along the top flange. External restraining forces were not applied. A maximum heating temperature of $1200^{\circ} \mathrm{F}$ was applied to all beams.

This experimental study considered a wide range of heating parameters and was by far the most extensive experimental study on heat straightening when it was published. Additionally, sophisticated monitoring equipment was implemented to capture as much scientific data throughout the experiments as possible. Roeder (1985 and 1986) suggested that future experiments should utilize more complex heat patterns, restraint conditions, structural shapes, and configurations. Future experiments should also perform extensive evaluations of the interaction between buckling and thermal stress. Results from this study are summarized as follows:

- Thermo-plastic deformation is dependent upon the temperature.

- Temperatures higher than $1330{ }^{\circ} \mathrm{F}$ are likely to produce (1) out-of-plane distortions, (2) plate buckling, and (3) pitting and surface damage to the steel.

- Increasing the Vee angle increases the occurrence of local buckling.

- Quenching may increase plastic rotation by $20 \%$ to $80 \%$.

- Quenching may reduce tendency towards local buckling. 
- Plastic deformation is developed by the Vee heat and occurs primarily within the heated area.

- Increasing the applied bending moment increases the plastic rotation

One disadvantage of this study was the multitude of heating parameters compared to the relatively limited number of experimental tests. This causes difficulty in accurately interpreting the effects that individual heating parameters have on the behavior of the test specimens.

Avent and Fadous (1988) conducted an extensive experimental program targeted on studying heat straightening repair for damaged steel bridge girders. The experimental tests were presented as part of Boudreaux's (1987) Master's thesis. The objective of the study was to optimize the development of engineered heat straightening repairs. The experimental study consisted of the application of 255, 18, 37, and 133 individual Vee heats to initially straight (undamaged) A36 grade steel plates, angles, channels, and wide flange sections, respectively. Prior research provided a limited number of data points with large variations (Weerth 1971, Horton 1973, Avent and Fadeous 1988). Therefore, the study focused on obtaining supplemental experimental data for undamaged plates and rolled shapes. The most effective heating sequences and patterns from Horton's (1973) study were used on the rolled shape tests. In all cases, the test specimens were allowed to cool in air. The experimental program consisted of heating temperature from $700{ }^{\circ} \mathrm{F}$ to $1500{ }^{\circ} \mathrm{F}$, depth ratios of $1 / 2,3 / 4$, and 1 times the width of the plate, Vee angles of $20^{\circ}, 30$ ${ }^{\circ}, 45^{\circ}, 60^{\circ}$, and $82^{\circ}$, and restraining moments (load ratios) of $0.0,0.16,0.25,0.37,0.50$ and 0.56 times the plastic moment capacity $\left(M_{p}\right)$.

This experimental study provided additional data related to the behavior of Vee heated undamaged plates and rolled shapes subjected to various heating parameters. The authors commented that additional experiments on plates and rolled shapes, analysis of the residual stress distributions of Vee heated plates and rolled shapes, and single and multiple damage-heat straightening repair comparisons of plates and rolled shapes are future research needs. The results of this experimental study revealed the following conclusions: 
- A linear relationship between the Vee angle and plastic rotation was verified for plates and rolled shapes.

- Vee depth ratios of $3 / 4$ and 1 produce slightly larger plastic rotations than a Vee depth ratio of $1 / 2$. However, the influence of the Vee depth on the plastic rotation requires further evaluation.

- Plate thickness and geometry have an insignificant effect on the plastic rotations.

- A maximum temperature of $1200{ }^{\circ} \mathrm{F}$ allows for some temperature variation during heating.

- More data points are needed to define relationship between restraining forces and plastic rotation.

Avent et al. (1992) completed a comprehensive experimental investigation of heat straightening repair of steel as part of Robinson’s (1991) Master's thesis. The objectives of the study were to quantify the various factors that affect the behavior of plates and rolled shapes subjected to single and multiple heat straightening repairs. The experimental study consisted of the application of 18, 18, and 32 individual Vee heats to undamaged angles, channels, and wide flanges, respectively, as well as 336, 29, 14, and 283 individual Vee heats to damaged plates, angles, channels, and wide flanges, respectively. All specimens were made from hot rolled A36 steel. The study incorporated both strong and weak axis bending. The experimental program consisted of heating temperatures of approximately $1200{ }^{\circ} \mathrm{F}$, Vee depth ratios of 3/4, and 1 times the width the plate, Vee angles of $20^{\circ}, 30^{\circ}, 45^{\circ}$, and $60^{\circ}$, and restraining moments $0.0,0.25,0.33,0.50$ times the plastic moment capacity $\left(M_{p}\right)$. Damage strains of $0 \varepsilon_{y}, 30 \varepsilon_{y}, 80 \varepsilon_{y}, 90 \varepsilon_{y}$, and $100 \varepsilon_{y}$ were considered and were computed using the radius of curvature method (Avent and Fadeous 1988). Multiple damage- heat straightening repairs of 2, 4, and 8 were applied to wide flange beams.

This experimental study was the first known to investigate the effects that heating parameters have on the behavior of initially deformed (damaged) test specimens. Additionally, it is the first study to perform multiple damage- heat straightening repairs. The study also indicated that damage strains of $100 \varepsilon_{y}$ can be successfully heat 
straightened. The authors, however, indicated that additional laboratory testing of rolled shapes and built up members typically found in bridges needs to be conducted and research on heat straightening repair of localized damage and fatigue characteristics of heat-straightened members is still lacking. Application of this research to actual repair situations and procedures for assessing the degree of damage are needed. The results of this study indicated that plastic rotations of undamaged and damaged plates, angles, and channel sections were found to be similar. Full-depth Vee heats did not cause more shortening of the member compared to three-quarter depth Vee heats.

De Bejar (1992a and 1992b) presented two experimental studies focused on assessing the behavior of Vee heated damaged plates and rolled shapes. The objective of these studies was to obtain the data for use in analytical studies, which were part of the project. The experimental program was designed to provide additional experimental data and not to investigate novel heating parameters. Only the Vee depth ratio ( 0.75 and 1.00 of the plate width) and the load ratio $\left(0.25,0.33\right.$, and 0.50 of the plastic moment capacity $\left.\left(M_{p}\right)\right)$ were varied. All test specimens were made from hot rolled A36 steel, heated to approximately $1200{ }^{\circ} \mathrm{F}$ and were subjected to $45^{\circ}$ Vee heats. The authors did not present any conclusions related to the behavior of the Vee heated test specimens.

\subsubsection{Residual Stresses}

Residual stresses are defined as stresses that remain in structural members after fabrication and rolling. The plastic deformations from the damage-heat straightening repair cycle also produce residual stresses. Several researchers have experimentally investigated the residual stresses resulting from heat straightening undamaged specimens (Roeder 1985, Avent and Fadeous 1988, and Avent et al. 1992). Only one study was found in the literature to address the residual stresses resulting from heat straightening damaged plates and rolled shapes (Avent et al. 1992).

Brockenbrough and Ives (1970) measured the residual stresses resulting from heat curving a plate girder using line heats. Residual stresses were measured in the girder using the "sectioning method" before and after the heat curving operation. In this method, two gage marks are punctured on the steel and measured. A narrow strip containing the two marks is milled out providing a stress relief within the strip. The gage marks are then 
remeasured and the change in length reflects the magnitude of residual stresses in the strip. The plate girders used by Brockenbrough and Ives (1970) were made from A36 steel. Results of this study indicate that the residual stresses in all parts of the plate girder were reduced except at mid-width of the flange. Tensile residual stresses approximately equal to the yield stress were found at the heated edges of the flange and compressive residual stresses were found in the web (Brockenbrough and Ives 1970). This study was the first found in the literature involving residual stresses resulting from the use of an oxy-acetylene torch. However, the applicability of these residual stress results to heat straightening research is limited.

Roeder (1985) evaluated the effects of residual stresses on heat straightening by comparing the plastic rotations of re-heated test specimens. He challenged the frequently suggested statement that residual stresses have a major impact on the plastic rotation of heat straightened specimens. Roeder (1985) stated, "If this is correct, different plastic rotations must be expected for virgin specimens that have been damaged due to prior loading and specimens which were deformed during earlier heating, since the residual stress will be quite different for each of these conditions”. The experimental program consisted of comparing three test specimens that had been heat curved one time to three test specimens that were subjected to similar heating parameters and heat curved twice. Roeder (1985) found an insignificant difference in the plastic rotation between the test specimens and concluded that residual stresses insignificantly affect the plastic rotation. These experimental investigations were conducted in the context of heat curving initially straight (undamaged) specimens and the heating parameters for the control and test specimens were "comparable" but not identical.

Avent and Fadous (1988) studied the residual stresses produced in heatstraightened specimens. The experimental program consisted of eight undamaged A36 plates (4" x 1/4" x 24") subjected to Vee heating. The Vee heated plates were subjected to four heating cycles using a depth ratio of 1 and a Vee angle of $45^{\circ}$. External restraining forces were not applied and the plates were heated to approximately $1200{ }^{\circ} \mathrm{F}$. Longitudinal residual stresses in each member were determined using the "sectioning method”. The results indicated that the edges of the Vee heated plates were found to be in tension and the centers were in compression. These stresses were significant in 
comparisons to an unheated control specimen. The authors suggested that additional experimental research of residual stresses is needed to study the magnitudes, distributions, and strain-aging effects of residual stresses on heat-straightened specimens.

Avent et al. (1992) conducted experimental investigations of the residual stress patterns in heat-straightened specimens. The experimental program consisted of testing undamaged and damaged plates, angles, channels and wide flange beams subjected to Vee heating. The beam specimens were damaged in both weak axis bending (Category W) and strong axis bending (Category S). Undamaged specimens were subjected to four heating cycles while the damaged specimens were subjected to the amount of heating cycles required for full repair. Several beam specimens were subjected to multiple damage-heat straightening repairs and then the residual stresses were determined. Longitudinal residual stresses in each member were determined using the "sectioning method”. All test specimens were made of A36 grade steel and were heated to approximately $1200{ }^{\circ} \mathrm{F}$. Residual stresses were calculated using both the assumed and the measured modulus of elasticity for some specimens. The magnitude and distribution of residual stresses in the unheated and Vee heated test specimens were analyzed and conclusions were presented. Presented below are the distinguished experimental investigations and results for each geometric shape that was considered.

Residual stress distributions were determined in eight undamaged and five damaged plate specimens (Avent et al. 1992). Heating parameters for the undamaged plates included Vee angles of $20^{\circ}, 45^{\circ}, 60^{\circ}$, and $82^{\circ}$, load ratios of 0.00 and 0.50 , and depth ratios of $3 / 4$ and 1 . Heating parameters for the damaged plates included Vee angles of $20^{\circ}, 45^{\circ}$, and $60^{\circ}$ degrees, load ratios of 0.25 and 0.50 , and depth ratios of $1 / 4,1 / 3$, and $1 / 2$. Average residual stresses were determined using the "sectioning method" for three different regions. The results from this study indicated that both the undamaged and damaged plates exhibited similar residual stress distributions as Roeder's (1985) theoretical distribution. The plates had a significantly larger plastic rotation during the first few heating cycles as apposed to further heating cycles. Residual stresses were determined to contribute to this selective behavior (Avent et al. 2000).

Residual stress distributions were determined in two undamaged angles, two damaged angles, and one undamaged channel (Avent et al. 1992). A Vee depth ratio of 1 
was used for all test specimens. The two undamaged angles were heated with Vee angles of $20^{\circ}$ and $45^{\circ}$ and without external forces. The two damaged angles were heated with Vee angles of $45^{\circ}$ and with load ratios of 0.50 and 0.33 . The undamaged channel was heated with a Vee angle of $45^{\circ}$ and with a load ratio of 0.50. Eight strips were tested from both the Vee heated leg and the strip heated leg of the angles. The results from this study indicate that similar residual stress patterns develop in damaged and undamaged angles. Further tests on the residual stress patterns of damaged-repaired channels and angles are needed.

Residual stress distributions were determined in four undamaged Category $\mathrm{W}$ and five undamaged Category $\mathrm{S}$ beam specimens. The Category $\mathrm{S}$ beam specimens were heated using either small $\left(20^{\circ}\right.$ and $\left.30^{\circ}\right)$ or large $\left(45^{\circ}\right)$ Vee angles. The results from this study indicate that the effects of the Vee angle and the load ratio on the residual stress patterns are small. Residual stresses were greater in the Vee heated beam specimens as compared to the unheated control specimen. The compressive residual stress in flanges typically increased with respect to the unheated control specimen, which is unfavorable for columns.

Finally, residual stress distributions were determined in four-damaged Category $\mathrm{W}$ and one damaged Category $\mathrm{S}$ beam specimens. The Category $\mathrm{W}$ beams were repaired using depth ratios of $3 / 4$, Vee angles of $45^{\circ}$, and load ratios of 0.5 . The Category $S$ beams were repaired using depth ratios of 1 , Vee angles of $45^{\circ}$, and load ratios of 0.5 . The four Category $\mathrm{W}$ beams were subjected to 1, 2, 4 and 8 multiple damage-heat straightening repairs before testing for residual stresses. The results from this study indicate that residual stress patterns are consistent for beams subjected to one and two damage-repairs and for beams subjected to four and eight damage-repairs. The residual stress patterns in the Category $\mathrm{W}$ damaged beams were opposite that of the undamaged beams (i.e. tension in the flanges and compression in the web), which is favorable for column repairs. The residual stress pattern in the Category $\mathrm{S}$ damaged beam was similar to that of the Category $\mathrm{S}$ undamaged beams but with greater compressive stresses. 


\subsubsection{Thermal and Structural Properties}

Several researchers have studied the effects of heat straightening on the structural properties of damaged-heat straightening repaired steel. These structural properties include the; modulus of elasticity, yield stress, tensile stress, ductility, fracture toughness, surface hardness, and fatigue strength. The majority of prior research has been conducted on undamaged steel specimens subjected to four or less heating cycles. One comprehensive study has performed structural property tests on initially damaged steel specimens and full-scale simulated girders that were completely heat straightened (Avent et al. 1992). The effects of heat straightening on the thermal and structural properties of steel are presented below:

\section{Thermal Expansion}

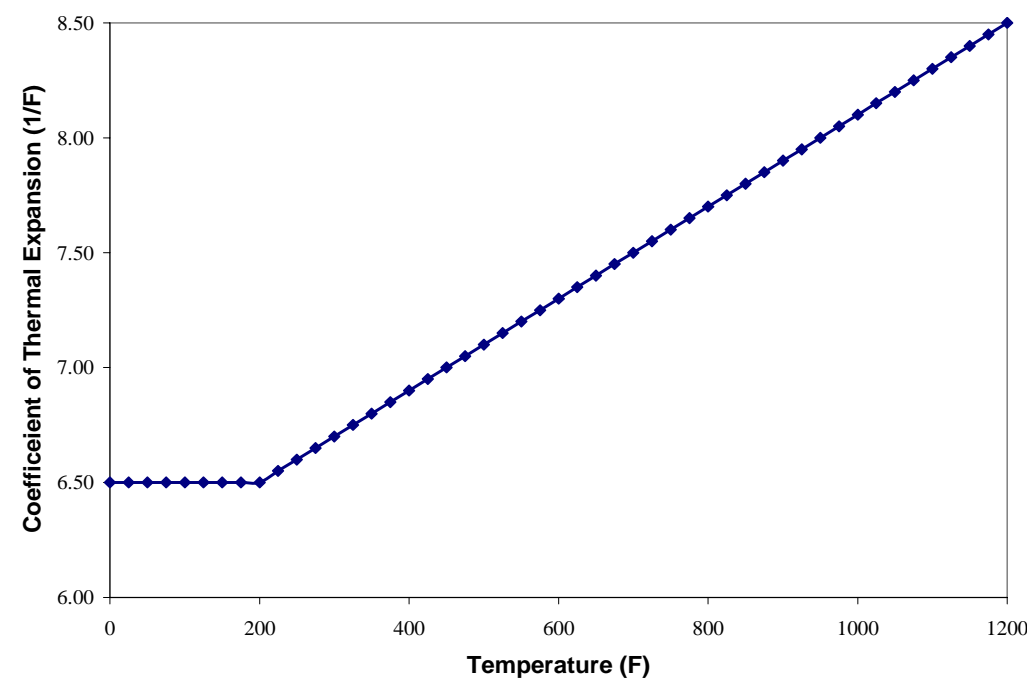

Figure 1 Variation of coefficient of thermal expansion versus temperature (Roeder 1986)

Thermal expansion is the most fundamental aspect of heat straightening steel. This property enables the steel member to expand and experience a net contraction in the direction of desired rotation. The coefficient of thermal expansion is the measure of rate of strain per degree of temperature. Figure 1 depicts the variation of the coefficient of thermal expansion for low carbon steel vs. temperature (Roeder 1985). Roeder (1985) has shown that for Vee heats, the coefficient of thermal expansion increases in a predictable 
manner up to $1600{ }^{\circ} \mathrm{F}$ for carbon steels. The coefficient of thermal expansion has shown to be linear and directly related to the temperature from approximately $250-1200{ }^{\circ} \mathrm{F}$ (Ditman 1961, Nichols and Weerth 1972, Blodgett 1972, Roeder 1986). Other research has shown that the coefficient varies in an unpredictable manner (For Chin 1962). It is also noted that surface damage (pitting) to steel and out-of-plane distortion becomes likely at temperatures over $1400^{\circ} \mathrm{F}$.

\section{Modulus of Elasticity}

The modulus of elasticity of steel varies inversely with temperature, i.e., as the temperature increases the modulus of elasticity decreases as shown in Figure 2. The equations used for in Figure 2 for the modulus of elasticity, assuming $E_{o}=30000 \mathrm{ksi}$ are provided in Equations (1)-(3) (Roeder 1985).

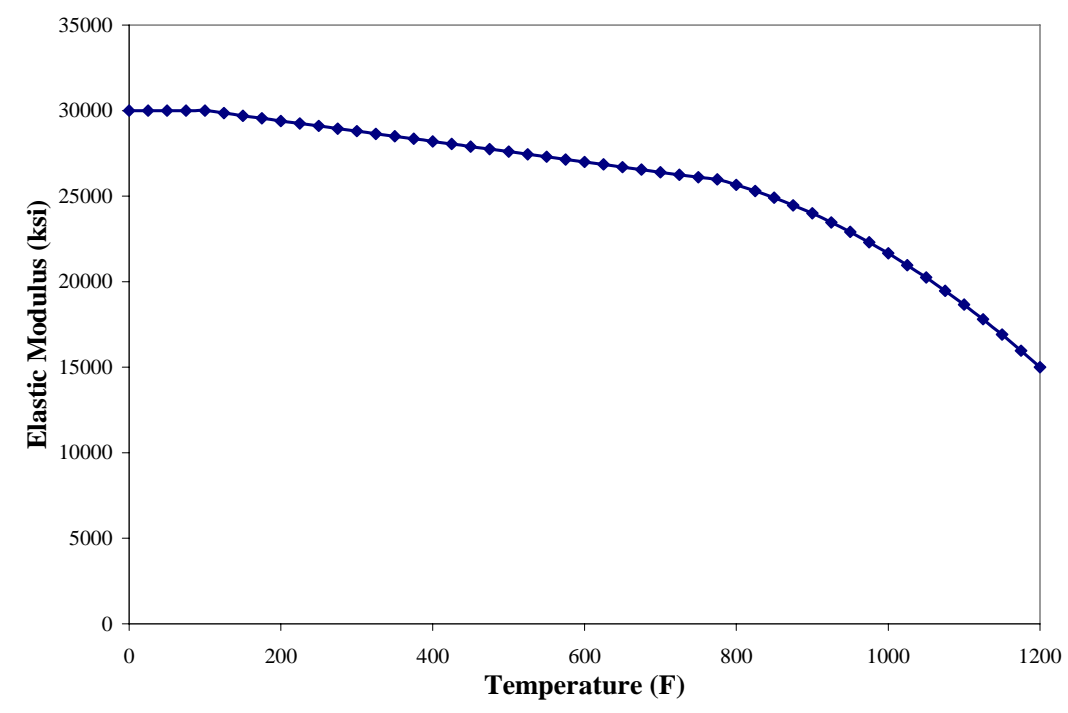

Figure 2 Variation of the modulus of elasticity vs. temperature (Roeder 1986)

$$
\begin{array}{ll}
\frac{E_{t}}{E_{o}}=1.0 & 0{ }^{\circ} \mathrm{F} \leq \mathrm{T} \leq 100^{\circ} \mathrm{F} \\
\frac{E_{t}}{E_{o}}=1.02-0.0002 \mathrm{~T} & 100^{\circ} \mathrm{F} \leq \mathrm{T} \leq 700^{\circ} \mathrm{F} \\
\frac{E_{t}}{E_{o}}=\left(500000-1333 \mathrm{~T}+1.111 \mathrm{~T}^{2}\right) * 10^{-6} & \mathrm{~T}>700^{\circ} \mathrm{F}
\end{array}
$$


At $1200{ }^{\circ} \mathrm{F}$, the modulus of elasticity of steel is approximately half of its typical value (FHWA 1998). Only three heat straightening studies have mentioned the calculation of the modulus of elasticity (Weerth 1971, Nichols and Weerth 1972, Horton, 1973). These studies implied that no appreciable difference could be measured between the heat-straightened specimen and the unheated specimen on mild steel specimens subjected to single Vee heat applications. However, these three studies were conducted on initially straight specimens that were typically subjected to four or less Vee heats. Recent research on damaged specimens indicates that a change in the modulus of elasticity is more apparent (Avent et al. 2001). The research indicated average reductions, as compared to the original modulus of elasticity, of $11-77 \%$ for damaged plates and 8$23 \%$ for damaged wide flange beams.

\section{Yield Stress}

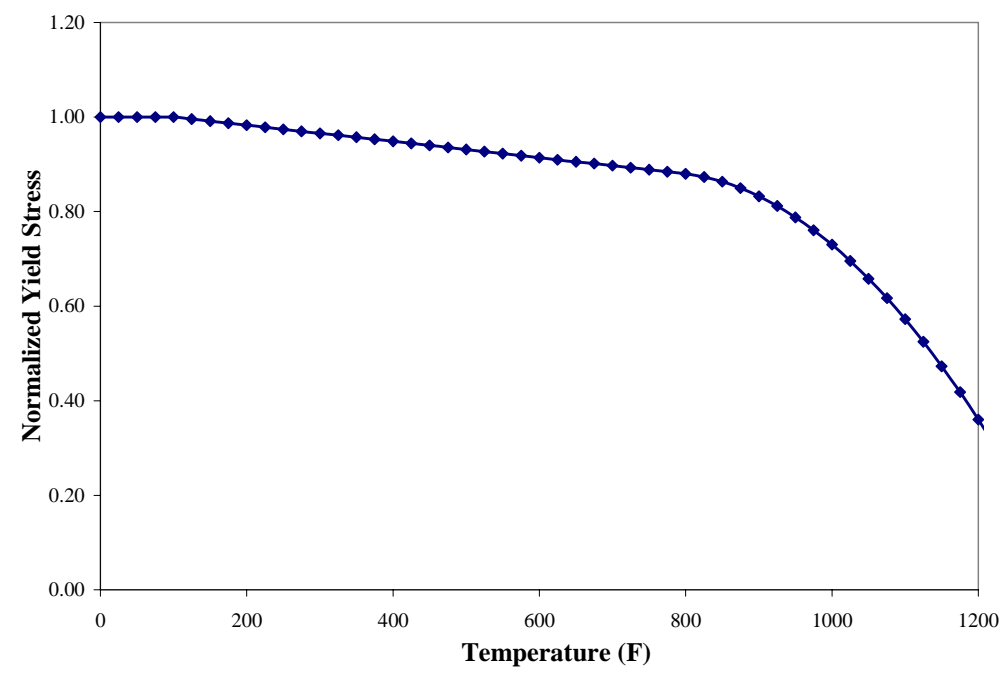

Figure 3 Variation of the yield stress vs. temperature (Roeder 1986)

Yield stress is the largest stress that steel can withstand before enduring plastic deformations. Research has revealed that the yield stress of steel is affected in two different ways due to heat straightening. First, there is a variation in the yield stress of steel as it is heated (FHWA 1998) as shown in Figure 3. The equations used for in Figure 3 for the normalized relationship of the yield stress are provided in Equations (4)-(6) (Roeder 1985). 


$$
\begin{array}{ll}
\frac{\sigma_{\mathrm{yt}}}{\sigma_{\mathrm{yo}}}=1.0 & 0{ }^{\circ} \mathrm{F} \leq \mathrm{T} \leq 100^{\circ} \mathrm{F} \\
\frac{\sigma_{\mathrm{yt}}}{\sigma_{\mathrm{yo}}}=1.0-(\mathrm{T}-100) / 5833 & 100^{\circ} \mathrm{F} \leq \mathrm{T} \leq 800^{\circ} \mathrm{F} \\
\frac{\sigma_{\mathrm{yt}}}{\sigma_{\mathrm{yo}}}=-\left(720000-4200 \mathrm{~T}+2.75 \mathrm{~T}^{2}\right) * 10^{-6} & \mathrm{~T}>800^{\circ} \mathrm{F}
\end{array}
$$

Second, heat straightening has a permanent effect on the yield stress of steel after it has cooled to room temperature. Researchers are interested in the long-term effects that heat straightening has on the yield stress of steel and ultimately on the integrity of the structure. Previous material property studies Nichols and Weerth 1972, Rothman 1973, Avent et al. 2000) have compared the results of undamaged heated specimens to unheated specimens. The results indicate that the yield stress of most heated structural steels increases. Only the quenched and tempered steels undergo reductions in yield stress after heat straightening. Table 1 displays the typical average percent changes in the yield stress from heat straightening initially straight specimens (undamaged). The specimens were subjected to four or less heating cycles with variations in heating parameters.

Table 1 Percent change in yield stress after heat straightening (FHWA 1998)

\begin{tabular}{|c|c|}
\hline Steel Type & Percent Yield Change \\
\hline \hline Carbon Steel & $10 \%$ \\
\hline High-strength, Low Alloy Steel & $2 \%$ \\
\hline Heat-Treated, High Strength Carbon Steel & $7 \%$ \\
\hline Quenched and Tempered Steel & $-6 \%$ \\
\hline
\end{tabular}

Tensile tests have been performed on damaged plates and damaged wide flange beams (Avent et al. 1992). Results of the tests vary considerably. All of the tests on coupons removed from the heated regions show increases in the yield stress compared to the coupons taken from the unheated regions. In one instance, a coupon taken from the apex portion of a Vee heated specimen resulted in an $88 \%$ increase in yield stress as compared to the unheated coupon. The majority of coupons taken from the apex of the Vee heating pattern exhibited the largest increases in yield and tensile stress. 


\section{Ductility}

Ductility is the mechanical property of steel, which allows it to plastically deform when subjected to large tensile stresses. It is usually calculated as the percent elongation over a two-inch gage length. Previous research (Avent et al. 1992) indicates a 10-20\% reduction in the ductility of heat straightened undamaged steel plates. This decrease in the test specimens is significant but the ductility of the specimens is still within an acceptable range. Table 2 displays the average percent reduction in ductility for several steel types that have been previously studied.

Table 2 Percent reduction in ductility after heat straightening (FHWA 1998)

\begin{tabular}{|c|c|}
\hline Steel Type & $\begin{array}{c}\text { Percent Ductility } \\
\text { Reduction }\end{array}$ \\
\hline Carbon Steel & $8 \%$ \\
\hline High-strength, Low Alloy Steel & $18 \%$ \\
\hline Quenched and Tempered Steel & $14 \%$ \\
\hline Quenched and Tempered Constructional-Alloy Steels & $11 \%$ \\
\hline
\end{tabular}

Avent et al. (1992) conducted ductility tests on damaged-repaired plates and wide flange beams. Test specimens were made of hot-rolled A36 steel. Results from these studies indicate that the reduction in ductility is significantly higher for single and multiple damage-heat straightening repairs than previously assumed from undamaged plate studies. Ductility test results on unheated strips revealed an initial percent elongation from 41-46\%. Results from the damage-heat straighten repaired plates revealed a final percent elongation from 32-37\% (FHWA 1992). This results in a 10-30\% reduction in elongation after the repair process. Results from the ductility tests were similar for all of the plates despite variations in the heating parameters, which include the degree of damage, jacking ratio, Vee depth, and the number of heats applied to heatstraighten the member. Heat straightened damaged wide flange beams exhibited ductility losses similar to that of the damaged plates. Strip tests from the heated regions resulted in 
percent elongations from $15-36 \%$. Unheated strips had percent elongations from $42-45 \%$. This resulted in an average ductility reduction of $15-66 \%$.

Putherickal (1992) conducted a field case study that involved testing the mechanical properties of the heat-straightened girder. It is the only such study found in the literature. The Iowa Department of Transportation (IDOT) removed the W30 x 108 girder from service for unknown reasons. The unheated portions of the web and flange were 34\% and 36\% elongation, respectively. The percent elongation of heated strips from the web and flange were $22.5 \%$ and $26 \%$ elongation, respectively. This constitutes a reduction of the ductility in the web and flange of $34 \%$ and $28 \%$, respectively.

\section{Fracture Toughness}

A Charpy V-notch test is a standard American Society of Testing Materials (ASTM 1999) test that determines the fracture toughness of steel coupons at specified temperatures. The Drop Weight Tear test is another test used to measure the fracture toughness of steel coupons. Fracture toughness of steel can be measured in three ways; (1) fracture energy using the Charpy V-notch test, (2) $T_{50}$ of upper shelf energy using Charpy V-notch test, and (3) fracture transition temperature using Drop Weight Tear test.

Several researchers have tested the notch toughness of steel subjected to heat straightening (Harrison 1952, Pattee 1969, Pattee et al. 1970, Avent and Brakke 1996, Till 1996). Results from tests, using various grades of steel plates, have indicated that there is an insignificant change in the upper shelf energy absorption before and after application of heat straightening (FHWA 1998). Considerable variations have been found within a steel grade when comparing the $T_{50}$ of the upper shelf energy using the Charpy V-notch test. Average values indicate that only the quenched and tempered low alloy steels have a significant positive shift. One researcher used the Drop Weight Tear test to evaluate the notch toughness of several grades of steel (Pattee 1969). This study showed that only the A517-A steel grade exhibited a positive shift, which indicates an increase in fracture sensitivity. Till (1996) performed 54 Charpy v-notch tests on A36 steel. This research was directed at assessing the effect of elevated temperatures on fracture critical steel members. He obtained an ASTM A36 steel plate (16” x 8” x 1") taken from the web

of a relatively undamaged W36 x 300 fracture critical uplift bridge member. The plate 
had sustained limited damage and was cut into nine specimens. The specimens were heated to a specified temperature for one-minute and then cooled using one of the following methods: under room conditions, compressed air, or water mist. The charpy specimens, removed from the heated specimens, were cooled for 24 hours at negative $15^{\circ} \mathrm{F}$ and then tested. Results from the tests indicate that most heated Charpy specimens show an increase in notch toughness as compared to the control specimen. Microscopic investigations revealed recrystallization of the grains had occurred in heated specimens.

\section{Rockwell Hardness}

The Rockwell Hardness test is a standard ASTM test used to measure the surface hardness of a material. Several researchers have conducted Rockwell hardness tests on initially straight (undamaged) heat straightened specimens (Pattee 1969, Pattee et al. 1970, Harrison 1952, Till 1996). The results of both Pattee (1969) and Harrison (1952) indicate that heat straightening did not significantly change the hardness values of the steel. These conclusions are based on laboratory testing of undamaged steel specimens subjected to a few heating cycles. Till (1996) performed Rockwell Hardness tests on the heated steel specimens. Results of the Rockwell Hardness tests indicate that heating the steel specimens had an effect on the hardness of the steel. Heating to $1100^{\circ} \mathrm{F}-1500^{\circ} \mathrm{F}$ decreased the average hardness of the steel. Metallurgical inspection verified that recrystallization of the grains had occurred, making the material less hard but more ductile. The author mentions that variations in the hardness were likely due to the cooling rate of the specimens (Till 1996). Hardness tests performed on damaged-heat straightened steel plates were not found in the literature.

\section{Fatigue Life}

Fatigue life is defined as the total number of alternating cycles at a specified stress level (fatigue limit) to cause the initiation of cracks of an appreciable critical size to appear. The fatigue endurance limit is the stress in which a theoretically infinite amount of cycles can be applied without the effects of fatigue. If pressed beyond this limit, the material with the presence of notches, holes, etc. is limited to a finite number of cycles before fatigue failure. The fatigue-crack-initiation threshold in various steels has been 
shown in studies to be associated with the yield and tensile strength of steel (Barson and Rolfe 1987).

One study on fatigue tests of heat-straightened members was found in the literature (American Railway Engineering Association 1946). Three eye bars made of A7 steel were fatigue cycled at 500,000 and 1,000,000 cycles. Significant difference in fatigue life was not indicated between the heat-shortened members and similar unheated members. Shanafelt and Horn (1984)suggested that non-redundant tension members should not be subjected to heat straightening repairs. They offered no scientific research or evidence in their report to back up such a recommendation. To date, there is a lack of scientific research or evidence that suggests that heat straightening reduces the fatigue life of steel members.

\subsubsection{Analytical Studies}

Review of analytical studies in the literature yielded research in the development of two theoretical models used to predict residual stress magnitudes/patterns and member behavior resulting from heat straightening. Numerous researchers (Brockenbrough 1970, Weerth 1971, Horton 1973, Avent et al. 1992) have performed experimental studies to provide the necessary data to develop and calibrate residual stress models, while others have concentrated their efforts on analyzing the behavior of heat straightened plates and rolled shapes. Simplistic (Holt 1965, Holt 1971, Moberg 1979, Avent and Fadous 1988) and comprehensive computer models (Brockenbrough 1970, Horton 1973, Roeder 1985, Roeder 1986, Weerth 1971) have been developed for predicting the behavior of heat straightened plates and rolled shapes. The usefulness of these models resides in their ability to accurately predict the number of heating cycles required to completely heat straighten a damaged girder. Therefore, this serves as a powerful tool for assisting structural engineers in designing heat straightening repair jobs. Theoretical studies that have been found in the literature are presented in this report.

Currently, analytical studies in the following areas are either inadequate or incomplete and need to be addressed by future researchers:

- Analytical formulations used for predicting member behavior for design 
- Procedures for assessing the degree of damage in terms of the reduced capacity of the structure

- Developing patterns and methodology for designing localized damage repairs

- Analytical formulations for predicting member behavior

\subsubsection{Theoretical Modeling}

Researchers have attempted to model the behavior of heat straightened steel plates and rolled shapes with theoretical models. In general, these models are developed and then compared to existing experimental data for accuracy. Both simple and complex theoretical models have been developed. Simple models, generally known as the Holt formula, are merely algebraic equations based on simplifying assumptions requiring minimal computational time. Complex models are aided with computer processing and are based on thermal and finite strip stress analysis. These models required significant computation time when published. Studies utilizing both models are summarized and presented below.

Holt (1965 and 1971) developed one of the first analytical models for predicting plastic behavior. This approach considers only the global action of the Vee heat. Holt (1965 and 1971) understood that the plastic flow resulting from the heating would result in a net contraction in the direction of confinement. The plastic strain for a specimen is computed by subtracting the elastic strain from the total free expansion for a given temperature. The formula is based on the following assumptions; uniformly distributed heating temperature of $1200^{\circ} \mathrm{F}$, ideal single axis confinement, and linear strain variation across the width of the plate. This equation is very basic and provides approximate values. The model neglects strain compatibility conditions for the Vee heat and assumes an unrealistic temperature distribution as well as the conductivity of steel (Roeder 1986). Additionally, the model neglects an estimate of the effect of restraint and the Vee depth. Moberg (1979) modified the Holt (1965 and 1971) formula to include the Vee angle, depth of the Vee, and the plate width.

Weerth (1971) and Horton (1973) developed analytical models for predicting residual stresses, strains, and curvature in steel plates and rolled shapes. Their models 
were based on the Duhamel strip analogy. The Vee heating pattern was divided into eight longitudinal strips and subjected to temperature distribution steps. Each strip (time step) is allowed to freely expand and then compress back to the initial length. This enforces compatibility between adjacent strips. A strain pattern is initially assumed and a trial and error method is used for determining the stress distribution that satisfies equilibrium. The resulting stress distribution becomes a load in the next step. Residual strains from the last step are used to calculate the theoretical camber induced in the plate from the Vee heat (Avent and Boudreaux 1987). This approach resulted in a good correlation between the analytical and experimental data. However, the trial and error solution required a large amount of computer time for the analysis. Horton (1973) did not have time to complete his analytical models for comparison with his experimental data. Some simplifying assumptions for the formulation that were considered include; initial distribution of residual stresses $\left(0.3 \sigma_{y}\right.$ in tension at plate ends, $0.3 \sigma_{y}$ in compression at the middle of the plate), linear strain distribution for any static temperature distribution, elastic-perfectly plastic stress-strain relationship for A36 steel, accuracy in temperature gradient in the plate during heating, control of the effective heating area, and lateral strains have an insignificant effect on the longitudinal stresses.

The initial residual stress distribution is common and widely accepted in the industry. Some of the above assumptions are sources for large errors. However, the resulting theoretical camber values compared well to the experimental camber values from the initially straight plates for both studies. Weerth (1971) concludes that full-depth Vee heats result in more desirable residual stress magnitudes and distribution compared to that of 3/4 depth Vee heats (Nichols and Weerth 1972). Horton (1973) concludes that the residual stress distribution in the test specimens reversed as compared to the initial stress distribution. Tensile yielding occurred at the apex of the Vee heats (flanges) and at several strip-heat locations in the web, while compressive stresses were found in the base of the Vee heats.

Roeder (1986) suggested a different approach that would capture both the local and global behavior of the Vee heating pattern. This theoretical model was developed to separately analyze the heat flow and elastic deformation problems. A finite difference model was employed to generate time independent temperature distributions. These 
profiles became steps for a non-linear finite element analysis. His results compared favorably well with the experimental data. However, the solution required large computational time.

De Bejar et al. (1992a and 1992b) conducted analytical studies on estimating the number of heats required to completely straighten a specimen. The theory of reliability and spectral analyses was employed to develop several equations based on minor axis bending. These equations are based on using the following heating parameters; $45^{\circ}$ Vee angle, 0.75 Vee depth ratio, 0.50 load ratio, and $1200{ }^{\circ} \mathrm{F}$ heating temperature. Results from the equations for damaged plates and wide flange shapes have provided excellent agreement with experimental studies. A model for predicting the number of heats based on the linearized theory of reliability was developed for when a sample experiment is known and when the damage angle and the heating conditions are provided.

Avent and Fadous (1988) developed a simple analytical formula for predicting the behavior of Vee heated plate specimens. The global formula was based on the Holt (1965 and 1971) formula but incorporated recent research (Roeder 1986) in regards to some of the assumptions used in the development of the formula. For instance, the perfect single axis confinement assumption has been proven to be inadequate. Therefore, the formula was improved using the experimental data from a research program (Avent and Fadous 1988). A preliminary analytical model for rolled shapes was developed. The authors report that the analytical and experimental results compared well, though further research on rolled shapes is necessary to refine the model. The assumptions that the analytical formula is based upon are:

- Longitudinal plastic strain occurs only in the Vee heated zone.

- Longitudinal strains are constant in throughout the width of the Vee heat.

- Planes defined by the Vee remain plane after heating and rotate about the apex of the Vee.

- Externally applied forces provide linear constraint with a load ratio of 0.323 providing perfect confinement.

- The internal constraint provides $45 \%$ of the external confinement. 
Most recently, Avent et al. (1992) expanded and refined the analytical formulations developed by Avent and Fadous (1992). A simple formula for predicting the plastic rotation from a single Vee heat was developed. The formula was developed as a function of the heating parameters used in the experimental program of the study. The researchers addressed the role of external restraining forces on composite girders. The theoretical model attempts to simplify the behavior of a heat straightened composite girder to that of a Vee heated plate. Multiplication factors for rolled shapes were developed based on the damage type and primary stiffening elements in the section. These factors were then calibrated for predicting the plastic rotation of rolled shapes using the simple plate equation. In addition, analytical studies were performed on full-size steel bridge components. For indeterminate structures, the members are subjected to a restraining moment that is induced in the bottom flange. Therefore, an additional multiplication factor was determined for the formula. All of the analytical formulas are merely algebraic equations and can be easily calculated. It is noted that all of the formulas were verified using experimental data from the same study.

\subsubsection{Full-Scale Studies}

Review of full-scale testing of heat straightened beams and columns in the literature resulted in field studies and prototype bridge tests. Field studies have been conducted on the following damaged bridges throughout the United States; Bothell Bridge, IA 130 Bridge, Lake Charles Bridge, and Crowley Bridge. These studies have addressed topics such as damage assessment, traffic control, application of heat straightening procedures, and plastic rotation data. The heat facility at Louisiana State University (LSU) has been a prime site for prototype bridge beam tests. This facility consists of a testing frame that was created to provide a controlled environment for testing full-scale bridge beams and axially loaded compression members and is capable of testing composite and non-composite beams spanning 20-feet. Studies performed at the facility have been used to investigate many issues including damage assessment, heating patterns and sequences, and plastic rotation. Summaries of the field studies and prototype bridge tests are presented below. 


\subsubsection{Field Studies}

\section{Bothell Bridge}

Moberg (1979) presented a masters thesis on damage assessment and contraction (heat) straightening of the Bothell Bridge in the State of Washington. The first part of his thesis outlines the general principles, tasks and procedures for damage assessment and the proper application of heat straightening necessary to repair the bridge. Moberg (1979) defined the damage assessment operation to incorporate public safety and protecting public property near the damaged structure, visually verifying the structural integrity of the structure, and obtaining the necessary data for engineering the repair.

The damage assessment analysis concluded that the following components of the Bothell Bridge needed repair; two beams (W33x118), the diaphragm frame, the deck, and the sidewalk bracket. The two wide flange beams were damaged about their weak-axis and repaired using Vee heats applied to the bottom flange. A web indentation was repaired using circumferential line heats. Only one heating sequence and load ratio was used during the heat straightening repair of the bridge. The beams were displaced in the direction of impact $4.01 \mathrm{in}$. and $0.75 \mathrm{in}$. The displacements from the damage and heating operations were measured using the taut line method. In this method, a taut line is strung from the ends of the member and offsets are measured between the string and the damaged member at specified distances. Spacing between offset measurements was not specified in the report. The author indicates that an accuracy of $\pm 0.01 \mathrm{in}$. is possible with this method. Due to time constraints, Moberg (1979) was only able to record heat straightening (plastic rotation) data at the end of each workday.

\section{IA 130}

The Iowa Bridge repair project was collaboration between Richard R. Avent of Louisiana State University and the Iowa Department of Transportation (IDOT) maintenance personnel. An over-height vehicle damaged the IA 130 overpass over I-80 as it was leaving the underpass. The bridge featured W36 x 170 continuous girders over supports with $190 \mathrm{ft}$. spans. The damage assessment revealed that the lower flange, which had apparently been damaged prior, was displaced approximately 7 in. out-of-plane. 
Local bulging had occurred in the web when the bolts from a diaphragm failed and three plastic hinges formed in the girder. The objectives of this project were to conduct a training program to teach IDOT personnel the correct heat straightening repair procedures, have the recently trained IDOT personnel successfully repair the damaged bridge, and measure and document the response of the heat-straightened girder during the repair.

The training program consisted of two days of presentations. IDOT personnel proceeded to repair the bridge under the supervision of Avent (Avent and Brakke 1996). The heat straightening crew successfully repaired the bridge in a 4-day period. A structural analysis of the girder system was performed to determine the proper placement of heating patterns and placement of the restraining forces. The restraining forces were limited such that the internal moment would not exceed 0.33 of the yield moment $\left(M_{y}\right)$ for the section (Avent and Mukai 2001). A maximum heating temperature of $1200^{\circ} \mathrm{F}$ was regulated to the yield zones. The heating sequence utilized to straighten the girder was a Vee heat applied to the bottom flange combined with strip heats to the web. Twenty-two heating cycles, where the first eight were within the diaphragm in place, were required to completely straighten the girder. After this was accomplished, the local bulge in the web was repaired using a star Vee pattern.

This study provided an excellent opportunity to obtain experimental data relating to the effects of various restraining forces applied to the lower flange of the girder. It was found that the use of the jacking forces expedited the plastic rotation per heating cycle until the diaphragm offered increasing restraint to the heat straightening process. The author also noted, "If the jacking/restraining forces are too high, a fracture might occur during straightening” (Avent and Brakke 1996). Results from this field study revealed the following conclusions:

- DOT personnel can successfully heat-straighten damage steel beams after a two-day training session.

- Future heat straightening repairs of beams with similar damage will result in a savings of $\$ 11,000$ using IDOT personnel versus a specialty contractor. 
- The theoretical modeling of the damaged beam over predicted the plastic rotation per heat cycle.

- Additional modifications to the theoretical formula may be necessary for more predictions that are accurate.

\section{Crowley Bridge}

Avent et al. (1992) conducted a field repair as part of a heat straightening research program. The repair was conducted on the Crowley Bridge in Louisiana. Research objectives for the case study were to successfully repair the damaged bridge using the state-of-the-art heat straightening bridge repair procedures and to measure and document the response of the heat-straightened girder during the repair.

Crowley Bridge featured four simply supported primary supporting girders, which spanned $75 \mathrm{ft}$. Initial damage assessment determined that an over-height vehicle struck the bottom flange of the girder, inducing an out-of-plane displacement of 2.95 in. The nearest diaphragm had been severely damaged and created a large local bulge in the web. A traffic control plan was designed to ensure the safety of the commuters and workers during the repair project. The project consisted of ten heating cycles that utilized Vee heats on the bottom flange with strip-heats on the web. After the fifth heating cycle, the heating pattern was redesigned since the bottom flange indicated no movement. It was determined that the lateral bracing was imposing a negative constraint on the thermal contraction effect (Avent et al. 1992). The heating patterns were revised in order to reobtain plastic rotation. Restraining forces were applied to the damaged girder using a hydraulic jack. The jack was positioned $2 \mathrm{ft}$. away from the impact point and created a restraining force of 12,900 lbs resulting in a restraining moment of $0.25 M_{p}$. The lateral displacement of the girder resulting from each heating cycle was measured and recorded. The bottom flange remained deflected 1.83 in. after the last heating cycle. The average lateral displacement per heating cycle was 0.11 in.

\section{Lake Charles Bridge}

A project implementing the latest heat straightening technology was performed on the Lake Charles Bridge in Louisiana (Avent and Fadous 1987). The project was a joint 
effort between Louisiana State University, the Louisiana Bridge Maintenance Division, and District 7. The Lake Charles Bridge features a simply supported noncomposite steel stringer (A-440) spanning $75 \mathrm{ft}$. Objectives of the repair project were to inspect the damaged bridge and assess the damage type and degree, design a heat straightening repair scheme, and implement the repair with Department of Transportation personnel.

The bridge was initially inspected to assess public safety and structural stability issues related to its usage. The inspection revealed that the bridge was stable and that the lower flange had displaced approximately 17 in. out-of-plane from the impact of an overheight vehicle. Diaphragms on both sides of the impact point had been partially crushed but most of the bolts were still in place. A decision was made to replace the diaphragms rather than repair them (Avent and Mukai 1998). The damage to the bridge was assessed using the taut line method. The lateral offsets were measured every $3 \mathrm{ft}$. except in areas of web bulges. These areas were measured on a six-inch-by-six-inch grid in order to capture the entire damage picture. A contour gauge was employed to obtain a continuous measure of curvature in areas of high localized yielding. This information was used to design a heat straightening repair plan.

The repair plan consisted of the selection of heating patterns for each damaged region, determining the length and location of line heats, determination of Vee angles, location and magnitudes of restraints, and an estimate of the number of heats required. Since the repair would require heat-straightening procedures to be implemented over the entire span of the beam, closure of the eastbound lanes was eminent. Therefore, the repair plan was construed such that the lanes would be alternately closed and the heat straightening operations would still be effective. Strong backs were employed to prevent the beam from falling if a crack initiated since all of the diaphragms were eventually removed.

Heat straightening of the beam was successful with the exception of two aspects. First, the dimple at the impact point on the lower flange of the beam had strain values that exceeded the recommended heat straightening guidelines (Avent 1992). It was decided not to repair the dimple but rather to grind and prevent stress concentrations. Second, the top flange of the beam had been displaced several inches from the impact and the heat straightening operation did not return the flange back into the deck slot. It was decided to 
have the bridge maintenance crew fill the gap with grout. This field study provides a stepby-step example of the repair procedure for heat straightening beams subjected to complex damage patterns. An interactive CD-ROM featuring the repair of this bridge is also available. A list of recommendations is also provided in the report for assisting DOT agencies in the implementation of heat straightening as a viable repair alternative.

\subsubsection{Prototype Bridge Studies}

A Heat Straightening Evaluation and Testing (HEAT) facility was constructed on the campus of Louisiana State University (Avent and Fadous 1987). This facility allows full-scale bridge girders to be studied without the need for traffic control or other safety issues associated with actual field studies. Two four-year studies have been conducted at the facility to date. The first study (1985-1988) involved composite girders, while the second study (1989-1992) included composite, non-composite girders and axially loaded truss members. These two extensive studies have documented the actual damage and repair behavior of full-scale bridge girders and axially loaded truss members.

The first study (Boudreaux 1987, Fadous 1987) included two different 20-ft. long composite wide flange beams that were subjected to two damage-repair cycles each (Cases SB-1 to SB-4). Case SB-1 and SB-2 involved the repair of a W10x39 girder damaged by static lateral loads. Case SB-3 and SB-4 involved the repair of W24x76 girders damaged by dynamic and static loads respectively. The prototype girders were simply supported with a concrete deck bolted to simulate composite action. Two diaphragms, one at each end, connected the test girder to the test setup. Damage was induced at mid-span with either a static or a dynamic lateral load. The dynamic lateral load was applied using a swinging pendulum.

The second study (Robinson 1991) extended the testing and analytical developments from the first study (Avent and Fadous 1988). The W24x76 girder from the first study (Avent and Fadous 1988) was subjected to two additional cycles of damage followed by heat straightening repair. It fractured during the fourth damage-repair cycle. In addition, a non-composite W24x76 beam was subjected to three damage-repair cycles. 


\subsection{HEAT STRAIGHTENING GUIDELINES}

Two major reports have been published to provide general guidelines for conducting heat straightening repair in the field. They are the NCHRP (Shanafelt and Horn 1984) and the FHWA (FHWA 1998).

The first comprehensive report on heat straightening addressed the general damage assessment of structures. In general, this report provides a rational approach to using heat straightening as a repair method (Shanafelt and Horn 1984). The report provides a set of guidelines for the damage assessment and heat straightening repairs of damaged steel bridge members. Shanafelt and Horn (1984) also presented a method for quantifying the damage of the steel member in terms of strain by using three offset measurements. The radius of curvature $(\mathrm{RC})$ along the edge of the damaged member is calculated by these three offset measurements along with their respective distances relative to each other. The authors suggest that measuring points be placed at one-foot intervals throughout the curved regions. In some cases, this interval could be too large and is incapable to capture the complete profile of the damaged area. Thus, the damage assessment could be significantly underestimated.

The calculated RC is compared to the RC of a typical cross-section when the extreme tension fiber has begun to undergo yielding. The calculated RC can then be expressed in terms of a multiple of the yield strain. Recommendations were made concerning upper strain limits for which heat straightening repairs should be made on primary tension members. Members having greater than five percent (approximately 42 times the yield strain $\left(42 \varepsilon_{y}\right)$ value for A36 steel) should not be straightened unless

additional splice material is added to the straightened areas. Additionally, repairs to primary tension members in severe fatigue critical areas (AASHTO stress categories lower than C) were limited to $15 \varepsilon_{y}$ (approximately the strain hardening state) even if the nominal strain was less than 5 percent.

If the severe critical details were present, the guidelines suggest that the damaged member could be straightened but would need to be strengthened with a minimum of 50 percent additional material. This suggestion is based on the premise that the member was probably designed for an allowable working stress of $0.50 \sigma_{y}$. Therefore, in reality, the 
heat straightened element could be neglected entirely and the recommended additional material would support the entire load.

The above guidelines suggest that primary tension members in severe fatigue critical areas with less than or equal to $15 \varepsilon_{y}$ can be straightened with the addition of more material. These strain limitations apply for tensile areas of damaged members. No limitations have been placed on compression members. It is crucial to keep in mind that no scientific studies have been conducted to establish the above limits. They are merely suggestions from the authors regarding the applicability of heat straightening based on strain limits.

The second comprehensive report that contributed to the development of heat straightening guidelines contains an engineering guide on the implementation of heat straightening for repairing damaged steel members (Avent and Fadous 1988). The guide addresses engineering issues related to the analysis and design of heat straightening repairs for damaged structural steel. The purpose of the guide is to provide the structural engineer with some analysis and design tools on heat straightening in a similar fashion that they are accustomed. The guide incorporates damage assessment, material assessment, and design of heat straightening repair sequence as well as tips for supervising field repairs.

Damage assessment is the first step in implementing heat straightening repairs in practice. The authors point out that the cause and damage type is influential on the design considerations for the repair (Avent and Fadous 1988). Evaluation and damage assessment methods are presented for primary and secondary damage. These damage assessment methods include the offset method, optical measurements, and image processing. A classification system for characteristic patterns of primary damage in rolled shapes is also defined. The system defines Mode I, Mode II, and Mode III, which correspond to weak axis bending, strong axis bending, and twisting about the longitudinal axis, respectively (Avent et al. 1991). Further sub-divisions of Modes I, II, and III are based on where the stiffening element is located (Avent and Fadous 1988). Classification of the structural configuration and a structural analysis is also important during the damage assessment stage. 
The authors provide material assessment guidelines for damaged members. The assessment includes investigating the resulting; yield stress, hairline fracture, yield lines, plastic hinges, radius of curvature, calculation of damage as a multiple of yield strain, local buckling or bulges, and evaluation of residual stresses affecting heat straightening. Guidance for designing a repair sequence includes; development of the restraint conditions, development of heating patterns, and temperature limitations. Guidelines for the field supervisor include; field safety, reviewing heating patterns, and monitoring heating temperature and the restraining forces being applied to the damaged member. It is recommended that the heating temperature be monitored by either temperature sensing crayons, contact pyrometers, or visual observation of steel color (Avent and Fadous 1988).

The third comprehensive report contributing to the development of heat straightening guidelines featured extensive experimental and analytical tests that were used to develop a companion report, "Design Procedures for Heat straightening Repairs: An Engineering Guide” (Avent 1992a). This companion report is a prototype-engineering guide for implementing heat straightening repairs. It supplements the previous engineering guide (Avent and Fadous 1988) with the addition of research obtained from the third comprehensive report (Avent et al. 1992). The following results were quantified and included in the new engineering guide:

- Formulas for calculating plastic rotations for plates, angles, channels and wide flange sections were developed.

- Residual stress patterns in damaged-heat straighten repaired members were quantified.

- Material properties in heated zones may vary significantly. Ductility in the heated zones may be greatly reduced.

- Damaged steel should not be repaired more than twice at the same location.

- Member shortening from Vee-heats (full and 3/4 depth) can be calculated.

- Restraining forces must be calculated based on both external and internal redundancy. Methods are used to analyze the restraining forces. 
- Composite girders, non-composite girders and axially loaded members have been studied and analytical models (plastic rotation) have been developed.

- Experimental results of successfully repaired specimens damaged up to $100 \varepsilon_{y}$ were documented.

Experimental studies have shown that the yield strength of heated steel is greatly reduced when heated (Brockenbrough 1970, Weerth 1971, Roeder 1985). Therefore, it is recommended that jacking forces should be gauged and limited to causing a moment in the heated zone to be less than 0.33 of the yield moment $\left(M_{y}\right)$ plus the residual stresses in the unheated section (Avent 1992). It is implicit in this recommendation that a structural analysis is performed and the moment capacity of the beam is readily available. It was also discovered that defining the degree of damage using "angle of damage" provided more consistent definitions of the damage as compared to using the radius of curvature (RC). Four offset measurements are used to define the "angle of rotation (degree of damage) between non-yielded portions on both sides of the plastic hinge yield zone" (Avent 1992).

Current DOT and FHWA heat straightening guidelines have been developed from the three major studies that were discussed above. The Federal Highway Administration (FHWA) sponsored a project, which complimented the Lake Charles Bridge repair (Avent and Mukai 1992, Avent and Mukai 1998, Avent and Mukai 2001). The objectives of the FHWA study were to develop training materials based on the results of the application of the latest heat straightening research on the Lake Charles Bridge repair. Deliverables from the study included a Technical Guide and Manual of Practice (FHWA 1992), as well as a video and multimedia CD-ROM computer program. The manual offers the latest guidelines to structural engineers for implementing heat straightening repairs for damaged steel bridge members. The CD-ROM computer program offers an interactive interface that offers a built-in calculator for designing heat straightening repairs. 


\subsection{CONCLUSIONS FROM LITERATURE REVIEW}

To date, great strides have been made in understanding the behavior and effect that heat straightening has on the structural properties of steel. Based on the above literature review, the following research areas have been investigated sufficiently:

- Development of heat straightening repair techniques for damaged steel members

- Development of guidelines and recommendations for heat straightening repair

- Estimating plastic rotations achieved during each Vee heat

- Predicting residual stresses caused by heat straightening in initially straight (undamaged) plates and rolled shapes

- Effects of heat straightening on the structural properties of initially straight (undamaged) plates and rolled shapes

Based on the above literature review, the following research areas are either inadequate or have yet to be addressed by researchers:

- Investigation of fatigue characteristics of heat straightened members

- Effects of heat straightening on the structural properties of initially damaged plates and rolled shapes (surface hardness and microstructure investigations are clearly lacking).

- Effects of heat straightening on the structural properties of different steel grades (most of the research work was conducted on A36)

- Effects of multiple damage and heat straightening repairs on the structural properties of steel

- Laboratory experiments on a greater variety of rolled shapes and built-up members commonly used in bridge design

- Recommendations and guidelines for evaluating and replacing (if necessary) steel beams subjected to multiple heat straightening repairs at the same location considering fracture and non fracture critical members 
- Recommendations and guidelines for evaluating the serviceability and load carrying capacities of steel bridges subjected to damage and repair

\section{Chapter 2 Literature Review of Heat Treatment}

\subsection{INTRODUCTION}

Heat treatment processes are used to produce changes in the metallurgical structure and the related material, structural, and surface texture properties of steel (Totten and Howes 1997). Different heat treatment processes have different effects on the resulting microstructure and structural properties including the strength, fracture toughness, and ductility of steel. Heat treatment is typically used in the steel manufacturing process to improve the quality or properties being produced. However, it can also be used to repair damage or rehabilitate older or used steels.

This research project conducted a synthesis study of heat treatment and its applications for repairing damaged or older bridge steels. Hence, this report presents a literature review of: (1) the metallurgy of carbon and high strength low alloy steels, (2) the different micro-constituents that may form as steel is heated and cooled, (3) the effects of damage on the microstructure, and (4) common steel heat treatments, (5) heat treatment after damage. The influence of various temperature ranges, micro-constituents, damage, and alloys on the transition temperature, recrystallization temperature, and resulting structural properties are discussed.

The organization of this report is as follows:

- Section 2.2 summarizes the metallurgy of steel at ambient and elevated temperatures. It comments on the effects of chemical composition and grain size on the structural properties and phase transformations.

- Section 2.3 discusses the formation of different micro-constituents as steel is cooled below the phase transformation temperatures.

- Section 2.4 discusses the effects of plastic deformation on the microstructure of steel.

- Section 2.5 reviews some of the commonly used steel heat treatments including their purpose, effects, and relevant parameters. 
- Section 2.6 presents the effects of heat treatment on damaged steels including the phenomenon of recovery, recrystallization, and grain growth.

\subsection{METALLURGY OF CARBON AND HSLA STEEL}

\section{Grain Structure of Low-Carbon Steel and High-Strength Low-Alloy Steels}

The research included studies of both low-carbon (LC, A36 and A7) steels and high-strength low-alloy (HSLA, A572 Gr. 50 and A588) steels:

- Low-Carbon steels contain up to $0.25 \%$ carbon along with various other elements such as manganese (up to 1.65\%), sulfur (up to 0.05\%), phosphorous (up to $0.04 \%$ ), silicon (up to 0.60\%), and copper (up to 0.60\%) (Totten and Howes 1997).

- High-Strength Low-Alloy steels have lower carbon contents (0.05-0.25\% C) then low carbon steels. The reduced carbon content acts to produce adequate formability and weldability. They also have manganese contents up to $2.0 \%$, and small quantities of chromium, nickel, molybdenum, copper, nitrogen, vanadium, niobium, titanium and zirconium added in various combinations. High-Strength Low-Alloy steels provide better mechanical properties and/or greater resistance to atmospheric corrosion than Low-Carbon steels. Section 2.2 discusses the effects of alloying elements in more detail.

Low-Carbon and High-Strength Low-Alloy steels each contain less than $0.8 \%$ carbon, which classifies them as hypoeutectoid steels. Hypoeutectoid steels consist of pearlite (described in greater detail on page 43) and proeutectoid ferrite. The properties of these micro-constituents and their effects on structural properties are discussed in detail later in Section 2.3. Figure 4 shows a schematic of the transformation of hypoeutectoid steels at elevated temperatures (Smith 2004). This schematic is valid only for steels that are cooled relatively slowly. For faster cooling rates, refer to information in Section 2.3. 


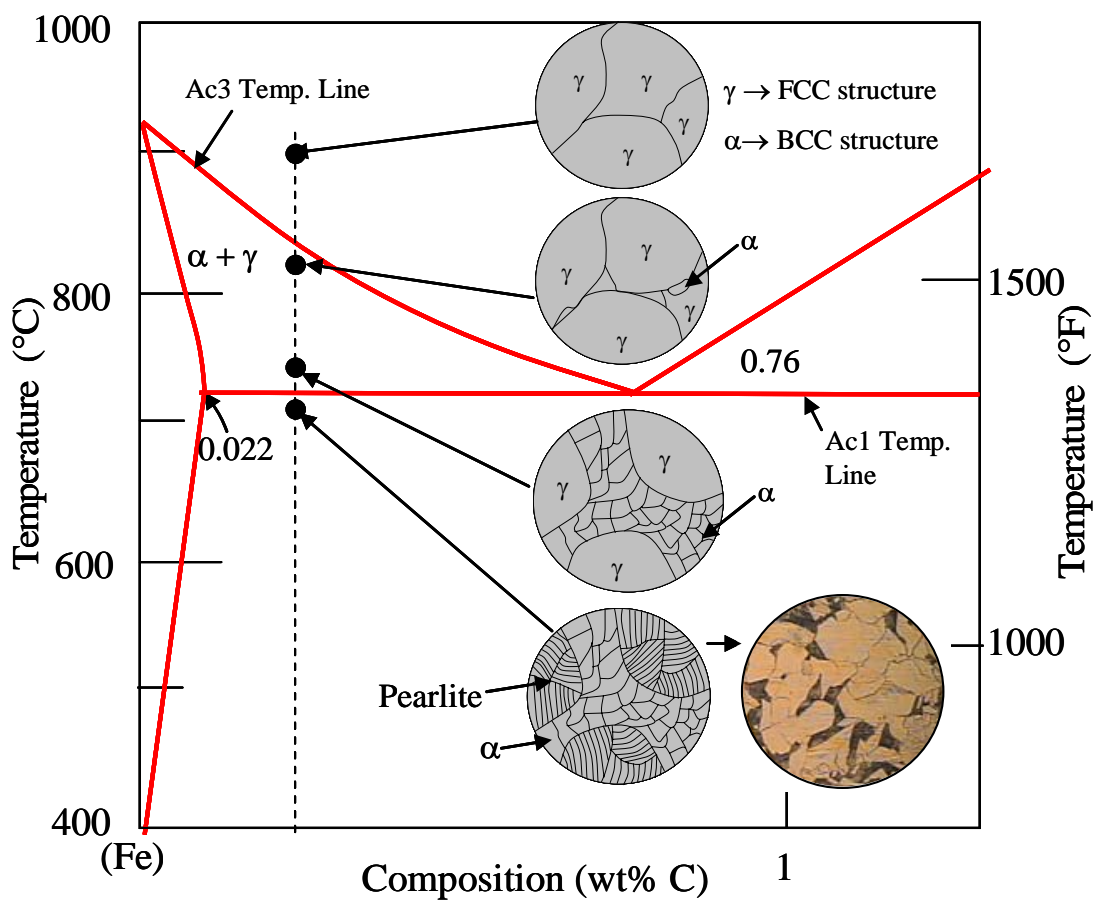

Figure 4. Phase transformation of hypoeutectoid plain-carbon steel

As shown in Figure 4, at high temperatures exceeding the stable austenite temperature (Ac3), the hypoeutectoid structure is in a stable $\gamma$-austenite phase. As the steel cools below the Ac3 temperature, proeutectoid ferrite will nucleate and grow at the austenite grain boundaries. As the steel continues to cool from the Ac3 temperature to the eutectoid temperature (Ac1), the amount of proeutectoid ferrite formed will continue to grow and the austenite will increase in percent carbon content. At the Ac1 temperature (approximately $1340^{\circ} \mathrm{F}$ ), the remaining austenite will transform into pearlite with consists of both ferrite and cementite $\left(\mathrm{Fe}_{3} \mathrm{C}\right)$ layers (Smith 2004). The ferrite that is present within the pearlite is referred as eutectoid ferrite to distinguish from proeutectoid ferrite. Thus, at ambient temperatures, a Low-Carbon or High-Strength Low-Alloy microstructure consists of proeutectoid ferrite and pearlite. The physical and structural characteristics of pearlite and other micro-constituents such as bainite and martensite are described in Section 2.3. 


\section{Effects of Alloying Elements on Phase Transformations and Properties}

The addition of several alloying elements affects the physical and structural properties of steel in a variety of ways. Alloying elements also affect the eutectoid temperature (Ac1) and the temperature that defines stable austenite (Ac3). The following equations can be used to predict the Ac1 and Ac3 temperatures as a function of different alloying elements (Krauss 1980), (Totten and Howes 1997):

$$
\begin{aligned}
& \mathrm{A}_{\mathrm{c} 1}=723-10.7(\% \mathrm{Mn})-16.9(\% \mathrm{Ni})+29.1(\% \mathrm{Si})+16.9 \% \mathrm{Cr}+290(\% \mathrm{As})+6.38(\% \mathrm{~W})\left({ }^{\circ} \mathrm{C}\right)(7) \\
& \mathrm{A}_{\mathrm{c} 3}=910-203 \sqrt{\% \mathrm{C}}-15.2(\% \mathrm{Ni})+44.7(\% \mathrm{Si})+104(\% \mathrm{~V})+31.5(\% \mathrm{Mo})+13.1(\% \mathrm{~W})\left({ }^{\circ} \mathrm{C}\right)(8) \\
& \mathrm{A}_{\mathrm{c} 1}=739-22(\% \mathrm{C})+2(\% \mathrm{Si})-7(\% \mathrm{Mn})+14(\% \mathrm{Cr})+13(\% \mathrm{Mo})+13(\% \mathrm{Ni})+20(\% \mathrm{~V})\left({ }^{\circ} \mathrm{C}\right)(9)
\end{aligned}
$$

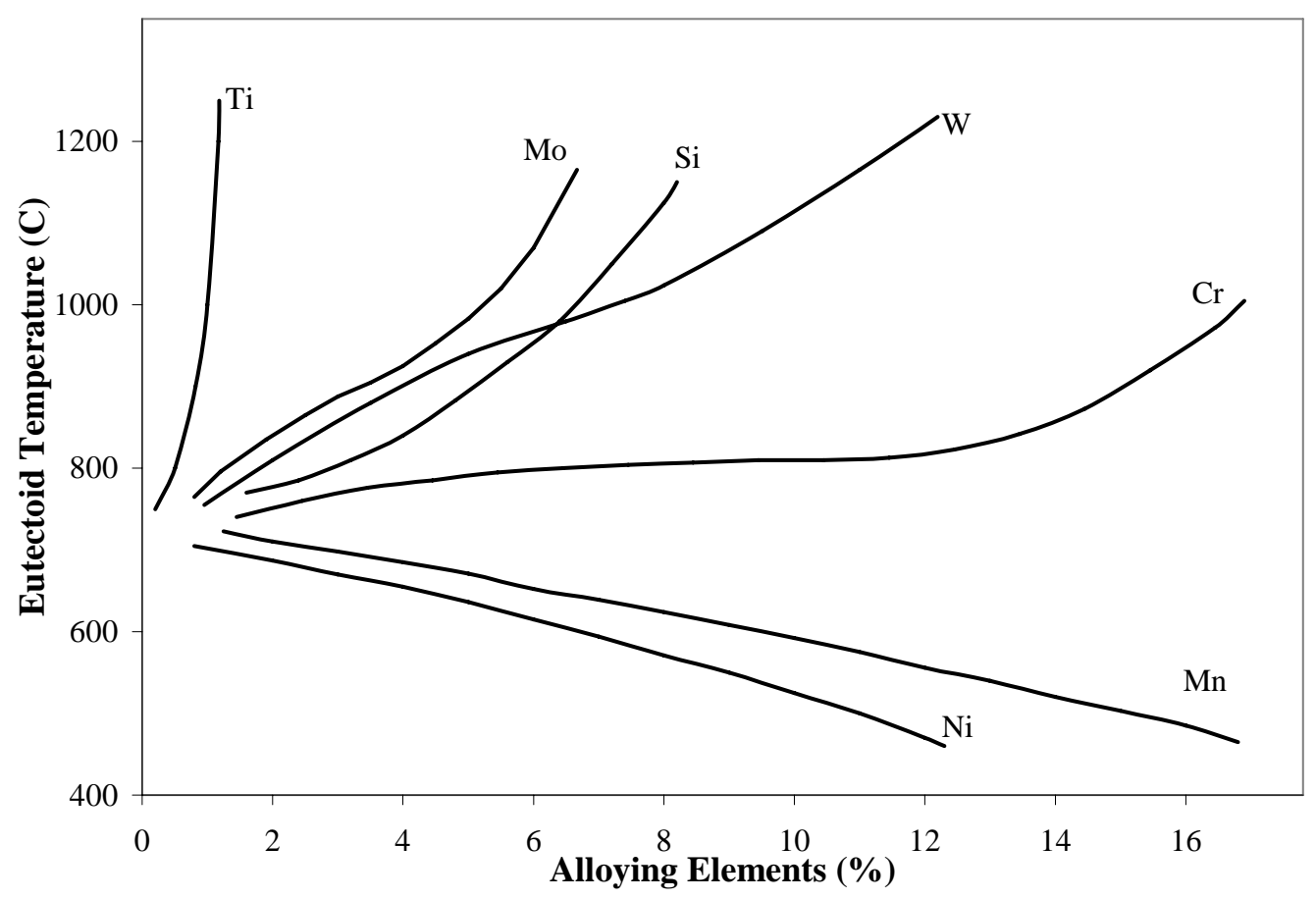

Figure 5. Effects of alloying elements on the Ac1 temperature (Callister 1997)

These equations are derived empirically from charts that have been developed to relate the effects of alloying elements on the critical transformation points. Figure 5 shows the effects of the most significant alloying elements on the Ac1 temperature (Callister 1997). Manganese (Mn) and nickel (Ni) are distinguished as austenite- 
stabilizing elements that lower the eutectoid temperature, and thereby expand the temperature range over which austenite is stable (Krauss 1980). Other alloying elements such as silicone (Si), chromium (Cr), molybdenum (Mo), arsenic (As), niobium (Nb), and tungsten (W) are distinguished as ferrite stabilizing elements (also called carbide-forming elements), which raise the eutectoid temperature of the steel and reduce the temperature range over which austenite is stable (Krauss 1980, Callister 1997). Vanadium (V) is an alloying element that delays the transformation of $\alpha$-ferrite to austenite and therefore raises the Ac3 temperature.

The different alloying elements also affect the physical and structural properties of steel. The effects of each are summarized below (Totten and Howes 1997, Callister 1997):

\begin{tabular}{|c|c|}
\hline $\begin{array}{l}\text { Carbon } \\
\text { (C) }\end{array}$ & $\begin{array}{l}\text { is essential to the formation of pearlite, spheroidite, bainite, and iron- } \\
\text { carbon martensite. Therefore, the hardness and strength of the steel } \\
\text { increases as the ductility and toughness of the steel decreases when more } \\
\text { carbon is added. }\end{array}$ \\
\hline $\begin{array}{l}\text { Aluminum } \\
\text { (Al) }\end{array}$ & $\begin{array}{l}\text { is widely used as a deoxidizer and a grain refiner. Al does not } \\
\text { significantly affect the material properties of steel. }\end{array}$ \\
\hline $\begin{array}{l}\text { Boron } \\
\text { (B) }\end{array}$ & $\begin{array}{l}\text { can significantly increase the hardenability of steel without decreasing } \\
\text { ductility. Its effectiveness is most noticeable at lower carbon levels. } \\
\text { Large amounts of B result in brittle, unworkable steel. }\end{array}$ \\
\hline $\begin{array}{l}\text { Cobalt } \\
\text { (Co) }\end{array}$ & $\begin{array}{l}\text { inhibits grain growth at high temperatures and significantly improves the } \\
\text { retention of temper and high-temperature strengths, resulting in an } \\
\text { increase in tool life. }\end{array}$ \\
\hline $\begin{array}{l}\text { Copper } \\
\text { (Cu) }\end{array}$ & $\begin{array}{l}\text { has a moderate tendency to segregate and therefore enhances } \\
\text { hardenability. } \mathrm{Cu} \text { is detrimental to the surface quality but improves the } \\
\text { corrosion resistance and the tensile properties in alloy and low-alloy } \\
\text { steels. }\end{array}$ \\
\hline $\begin{array}{l}\text { Chromium } \\
\text { (Cr) }\end{array}$ & $\begin{array}{l}\text { is a strong carbide former, which increases hardenability and corrosion } \\
\text { resistance. Cr is the most efficient of the common hardening elements } \\
\text { and is frequently used with a toughening element such as nickel (Ni) to } \\
\text { produce superior mechanical properties. }\end{array}$ \\
\hline $\begin{array}{l}\text { Lead } \\
(\mathrm{Pb})\end{array}$ & $\begin{array}{l}\text { Lead }(\mathrm{Pb}) \text { is sometimes added to carbon and alloy steels to improve } \\
\text { machinability. } \mathrm{Pb} \text { does not have a significant effect on the material } \\
\text { properties of steel. }\end{array}$ \\
\hline $\begin{array}{c}\text { Manganese } \\
\text { (Mn) }\end{array}$ & $\begin{array}{l}\text { Manganese }(\mathrm{Mn}) \text { is present in virtually all steels. It is essentially a } \\
\text { deoxidizer and desulfurizer. Mn increases the strength, hardness, also } \\
\text { favorably effects forgeablity, and weldability. }\end{array}$ \\
\hline $\begin{array}{l}\text { Molybdenum } \\
\text { (Mo) }\end{array}$ & $\begin{array}{l}\text { Molybdenum (Mo) is a strong carbide former. The addition of Mo } \\
\text { produces fine-grained steels, increases the depth of hardness, and } \\
\text { improves the fatigue strength. Mo also increases corrosion resistance and } \\
\text { is thus used with high-alloy Cr steels and with austenic Cr-Ni steels. }\end{array}$ \\
\hline
\end{tabular}




\begin{tabular}{|c|c|}
\hline $\begin{array}{c}\text { Nickel } \\
(\mathrm{Ni})\end{array}$ & $\begin{array}{l}\text { Nickel (Ni) is a ferrite strengthener and toughener that improves the } \\
\text { ductility, toughness, and the strength of the steel. }\end{array}$ \\
\hline $\begin{array}{l}\text { Niobium } \\
(\mathrm{Nb})\end{array}$ & $\begin{array}{l}\text { Niobium (Nb) is a ferrite former that reduces the austenite phase. Small } \\
\text { amounts of Nb increase the yield strength and the tensile strength of } \\
\text { steel. The increased strength may be accompanied by considerably } \\
\text { reduced notch toughness unless special measures are employed to refine } \\
\text { grain size during hot rolling. }\end{array}$ \\
\hline $\begin{array}{l}\text { Phosphorous } \\
\text { (P) }\end{array}$ & $\begin{array}{l}\text { Phosphorous }(\mathrm{P}) \text { slightly increases the strength and hardness of the steel. } \\
\text { A large quantity decreases ductility and fracture toughness. A higher } \mathrm{P} \\
\text { content is specified in low carbon free-machining steels to improve } \\
\text { machinability. }\end{array}$ \\
\hline $\begin{array}{l}\text { Silicon } \\
\text { (Si) }\end{array}$ & $\begin{array}{l}\text { Silicon (Si) is one of the principal deoxidizers used in steel making. It has } \\
\text { a determinable effect on the surface quality of low-carbon steels. When } \\
\text { the } \mathrm{Si} \text { content of steel is below } 0.30 \% \text {, it dissolves completely in ferrite, } \\
\text { increasing the strength without greatly decreasing ductility. }\end{array}$ \\
\hline $\begin{array}{l}\text { Sulfur } \\
\text { (S) }\end{array}$ & $\begin{array}{l}\text { Sulfur }(\mathrm{S}) \text { has a detrimental effect on transverse ductility, fracture } \\
\text { toughness, weldability, and surface quality, but only has a slight effect on } \\
\text { longitudinal mechanical properties. }\end{array}$ \\
\hline $\begin{array}{l}\text { Tin } \\
\text { (Sn) }\end{array}$ & $\begin{array}{l}\text { Tin (Sn) in relatively small amounts is harmful to steels for deep } \\
\text { drawing. The effects of Sn in the amounts usually presented are } \\
\text { negligible. }\end{array}$ \\
\hline $\begin{array}{l}\text { Titanium } \\
\text { (Ti) }\end{array}$ & $\begin{array}{l}\text { Titanium (Ti) is used widely in stainless steels as a carbide former for } \\
\text { stabilization against intergranular corrosion. Ti increases creep rupture } \\
\text { strength. }\end{array}$ \\
\hline $\begin{array}{l}\text { Tungsten } \\
\text { (W) }\end{array}$ & $\begin{array}{l}\text { Tungsten (W) is a very important carbide former. It improves toughness } \\
\text { and prevents grain growth. }\end{array}$ \\
\hline $\begin{array}{l}\text { Vanadium } \\
\text { (V) }\end{array}$ & $\begin{array}{l}\text { Vanadium (V) is an excellent deoxidizer, carbide former, and grain } \\
\text { refiner. It dissolves in ferrite, imparting strength and toughness. V } \\
\text { increases fracture strength on one hand and improves notch sensitivity on } \\
\text { the other. }\end{array}$ \\
\hline $\begin{array}{l}\text { Zirconium } \\
\text { (Zr) }\end{array}$ & $\begin{array}{l}\text { Zirconium (Zr) is added to killed high-strength low-alloy steels to obtain } \\
\text { improvements in inclusion characteristics that improve ductility in } \\
\text { transverse bending. }\end{array}$ \\
\hline
\end{tabular}

\section{Effects of Grain Size on the Structural Properties of Steel}

The effects of the microstructure grain size on the structural properties and fracture toughness of steel are as follows:

- In general, a coarse-grain structure (large) is not as desirable as a fine-grain structure (small) for most steels as it leads to lower strengths and only moderately decreased ductility. The tendency to fracture also increases in a more coarse-grained structure (Smith 1993). 
- Finer-grained steels have more grain boundaries that act as barriers to dislocations. Therefore, a higher density of grain boundaries will produce higher yield and tensile stresses (Smith 1993). Plane strain fracture toughness normally increases with a reduction in grain size when composition and other microstructure variables are maintained constant (Callister 1997). Decreasing the grain size significantly decreases the transition temperature, which is the temperature that governs the ductile to brittle fracture (Totten and Howes 1997). Hence, decreasing the grain size typically increases the strength and fracture toughness of steels.

\subsection{ISOTHERMAL AND CONTINUOUS COOLING TRANSFORMATIONS}

\section{Formation of Different Micro-constituents}

When steel is cooled from a temperature higher than the phase transformation temperatures Ac1 or Ac3, a number of micro-constituents form depending on the cooling rate. Two types of time-temperature-transformation (TTT) diagrams are used to predict the formations of different micro-constituents in steel after cooling below the Ac1 temperature. These are as follows:

- An isothermal TTT diagram is a plot of temperature vs. logarithm of time for steel alloys of definite composition (Callister 1997). It is used to determine when transformation begins and ends for an isothermal (constant temperature) heat treatment.

- A continuous cooling transformation (CCT) diagram is a plot of temperature vs. logarithm of time for a steel alloy of definite composition. It is used to determine when transformations begin and end when a previously austenized alloy is cooled continuously at a specified rate.

When compared to isothermal TTT diagrams, CCT diagrams show longer times and lower temperatures required for forming the different micro-constituents. A number of isothermal TTT diagrams for various steels were found in the literature (USSC 1943, ASM 1977). However, not as much research has been performed for the development of CCT diagrams. Derivation of a CCT diagram is a rather tedious task, and for many 
purposes not essential because of the fundamental relationship between TTT and CCT diagrams (USSC 1943).

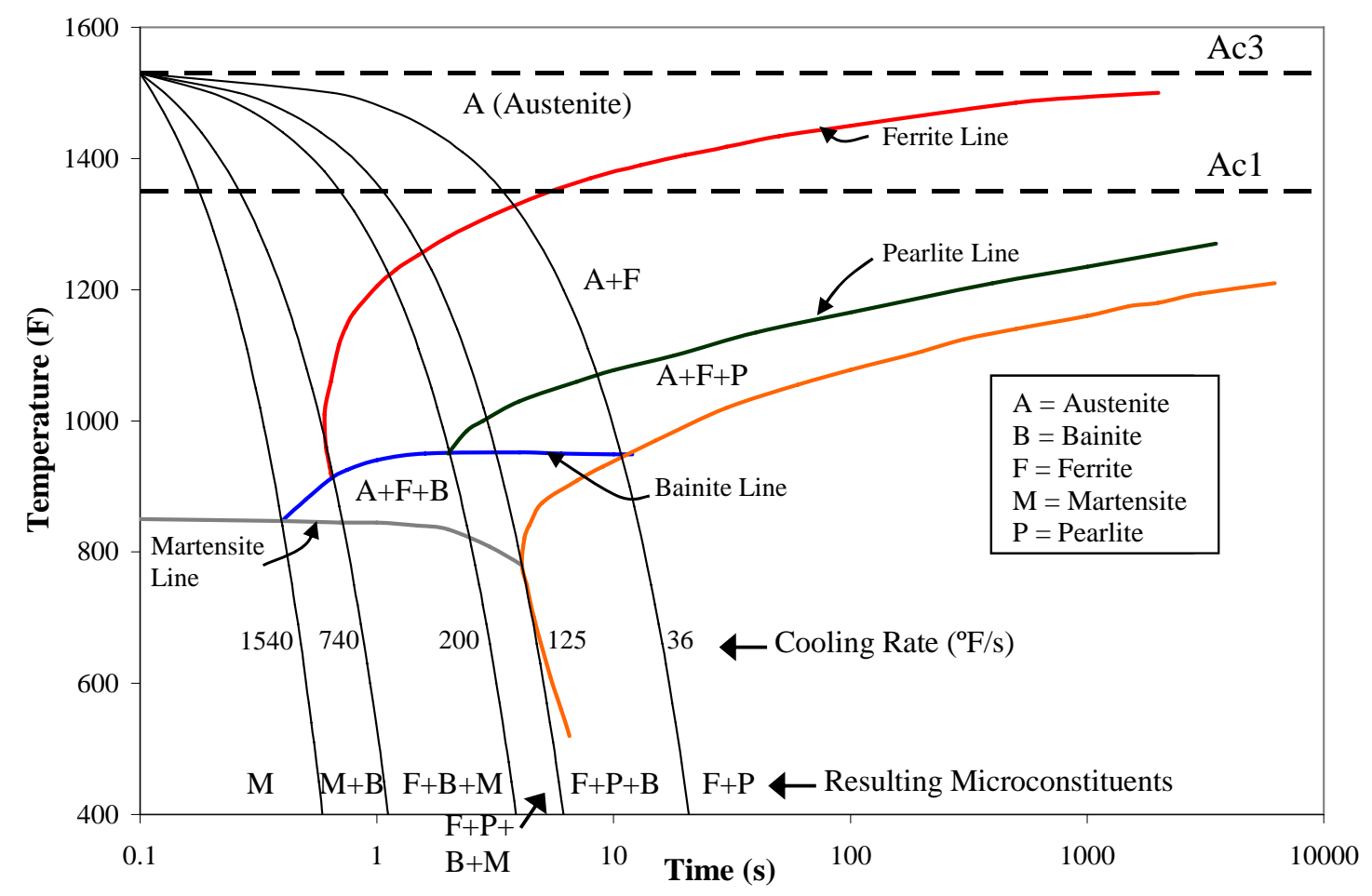

Figure 6. Superimposed continuous cooling diagram of a AISI $(0.12 \% \mathrm{C})$ steel

Figure 6 shows a CCT diagram for AISI 1010 steel, which is a low carbon steel with chemical composition similar to A36 steel (ASM 1977). It contains 0.12\% C, 0.50\% Mn, and $0.16 \%$ Si. The Ac3 and Ac1 temperatures in Figure 6 were calculated from the chemical composition using Equations (7) and (8) The time axis on continuous cooling diagrams begins when the steel temperature falls below the Ac3 temperature.

The microstructure is initially in the $\gamma$-austenite phase and can form various micro-constituents dependent on the cooling rate. The critical cooling rates required for the formation of bainite and the formation of martensite are shown in Figure 6. The cooling rates represent the lower and upper rates for which different microstructures may form for the AISI 1010 steel. If the steel cools in between two rates specified in Figure 6, the micro-constituent combination indicated on the bottom will form.

\section{Pearlite}


Pearlite consists of layers of $\alpha$-ferrite and cementite $\left(\mathrm{Fe}_{3} \mathrm{C}\right)$ layers. Cementite is much harder and more brittle than ferrite (Callister 1997). Thus, an increased amount of pearlite increases the hardness, yield strength, and ultimate strength of steel. However, both the ductility and the toughness of the material will decrease. Dependent on the cooling period, the resulting pearlite may be fine or coarse grained. A more coarsegrained pearlite microstructure will form upon longer cooling periods. Slower cooling periods produced relatively thick layers of both the $\alpha$-ferrite and $\mathrm{Fe}_{3} \mathrm{C}$. Fine pearlite is harder and stronger, yet more brittle than coarse pearlite.

\section{Bainite}

Bainite is an austenitic transformation product found in some steels. It forms at temperatures between which pearlite and martensite forms (Callister 1997). The production of bainite on the continuous cooling transformation diagram is shown in Figure 6. A bainite microstructure consists of both -ferrite and a fine dispersion of cementite. A microstructure consisting of bainite does not necessarily consist of proeutectoid ferrite. Since bainite has a finer structure, it is generally stronger, harder, and consequently more brittle than pearlite. Bainite micro-structures exhibit a desirable combination of strength and ductility for a number of engineering applications (Callister 1997) but is often not beneficial for the required ductility of steel beam bridges.

\section{Martensite}

Martensite is formed from austenized iron-carbon alloys that are rapidly cooled or quenched to a relatively low temperature (Callister 1997). In other words, martensite is a nonequilibrium single-phase structure that results from the diffusionless transformation of austenite. For alloys containing less than 0.6 wt\% Carbon (LC and HSLA), the martensite grains form as long and thin plates that are aligned side by side and parallel to each other. The formation of martensite can be predicted using a continuous cooling transformation diagram as shown in Figure 6. If the steel cools faster than the indicated curve on the far left in Figure 6, the iron-carbon alloy will completely transform to martensite. Figure 6 indicates that martensite may be accompanied by ferrite, bainite, and to some extent pearlite (Smith 2004). 
Martensite is the hardest, strongest, and the most brittle form of micro-constituent for an iron-carbon alloy. The hardness and strength of martensite increase with an increase in carbon content. Martensite has negligible ductility (Callister 1997). Therefore, the formation of martensite during heat treatment of a steel bridge needs to be strictly avoided.

\subsection{EFFECTS OF PLASTIC DEFORMATION ON STEEL MICROSTRUCTURE}

Plastic deformation is commonly classified as cold-work or hot-work of metals. In a cold-worked deformation, there is no accompanying recrystallization. Hot-working has recrystallization occurring simultaneously. Plastic deformation is the product of movement of individual crystal defects called dislocations (ASM 1973). A very large number of dislocations exist in deformed metal. Dislocation density can be uniform or highly variable from point to point. The variety of dislocations gives rise to a variety of large-scale deformations, including slip and twinning. The crystallographic plane along which the dislocation line transverses is the slip plane. Slip lines are visible traces of slip planes, which can be seen on the surface of the steel (ASM 1973). A slip line represents a transfer of the material on opposite sides of the slip plane. Planer slip refers to slip lines that are straight, whereas wavy slip refers to slip lines that are irregularly shaped. Wavy slip lines indicate a series of microscopic shears in two or more intersecting slip planes such as that caused by the departed cross slip of a screw dislocation.

Deformation and slip in a polycrystalline material (one composed of more than one single crystal such as steel) is somewhat complex (Callister 1997). Due to random crystallographic orientations of the numerous grains, the direction of slip varies from one grain to another. For each, dislocation motion occurs along the slip system that has the most favorable orientation. According to Callister (1997), plastic deformations should result in the production of slip planes and grain elongation along the direction in which the specimen was extended. 


\subsection{HEAT TREATMENTS OF STEEL AND THEIR RELATION TO HEAT STRAIGHTENING}

A variety of heat treatments are used to enhance the material properties of steel. The purpose of this section is to discuss the most common heat treatments. The treatment processes summarized in this section include; soft or spheroidizing annealing, process annealing, isothermal annealing, normalizing, tempering, and thermomechanical treatments. Such heat treatments change the micro-strucuture aspects of steel and therefore enhance or deteriorate structural properties.

\section{Soft or Spheroidzing Annealing}

Soft or spheroidizing annealing is an annealing process at temperatures slightly above or below the Ac1 temperature, with subsequent cooling (Totten and Howes 1997). The steel considered for soft annealing typically has a carbon content of at least $0.60 \%$, which would not include Low-Carbon or High-Strength Low-Alloy steels. The process is generally considered for hypereutectoid steels (\%C $>0.80 \%$ ). The aim of soft annealing is to produce a soft structure by changing all hard constituents such as pearlite, bainite, and martensite into a structure of spheriodized carbides (spheroidite) in a ferritic matrix.

Soft annealing is not related to heat straightening due to the required period for developing the spheroidite microstructure. It is also not relevant for Low-Carbon and High-Strength Low-Alloy steels. The required period is typically between 18-24 hours (Callister 1997). The kinetics of spheroidite is not included on isothermal or continuous cooling transformation diagrams. Therefore, spheroidite was not distinguished in Section 2.3 .

\section{Process Annealing}

Process annealing is usually applied to hypoeutectoid steels with up to $0.3 \%$ C. The steel is heated to temperatures of typically $550-650^{\circ} \mathrm{C}\left(932-1202^{\circ} \mathrm{F}\right)$, which are below the Ac1 temperature. The steel is held at these temperatures for the necessary time and then cooled at a desired rate. Process annealing is frequently referred to as a "stressrelief” or "recovery” treatment since it partially softens cold-worked steels by relieving internal stresses (residual stresses) from cold working (Smith 2004). This process will not cause any phase changes but recrystallization may occur (Totten and Howes 1997). 
Process annealing is fairly related to heat straightening as both relieve the damage induced after cold working and similar temperature ranges are used. The maximum temperature limit for heat straightening is typically $1200^{\circ} \mathrm{F}\left(650^{\circ} \mathrm{C}\right)$. The intent of the two processes are somewhat different as heat straightening is used to straighten the cold worked members and does not consider the removal of internal residual stresses. Totten and Howes (1997) indicates that the soaking time required for process annealing is a much longer period than could be considered when heat straightening. The soaking times for process annealing are typically measured in hours.

\section{Isothermal Annealing}

Hypoeutectoid steels that are used for carburizing as well as medium-carbon structural steels that are used for hardening and tempering are often isothermally annealed for better machinability (Totten and Howes 1997). An isothermally annealed structure should have; a high proportion of ferrite, uniformly distributed pearlite, fine lamellar pearlite grains, short pearlite lamellae, and coarse ferrite grains. Isothermal annealing includes austenitizing, followed by fast cooling to the temperature range of pearlite formation (about $1200^{\circ} \mathrm{F}\left(650^{\circ} \mathrm{C}\right)$ ), holding at this temperature range until the complete transformation of pearlite is achieved, and cooling to room temperature at a arbitrary cooling rate. Isothermal annealing is clearly unrelated to heat straightening since heat straightening is characterized by continuous cooling rates.

\section{Normalizing}

Low-Carbon and High-Strength Low-Alloy steels that have been plastically deformed consist of pearlite grains that are irregularly shaped and relatively large, but vary substantially in size. Normalizing is a heat treatment process consisting of austenitizing (heating to temperatures in the range to cause an austenite microstructure) at temperatures 30-80 C (86-176 F) above the Ac3 temperature (for hypoeutectoid steels) followed by slow cooling (Totten and Howes 1997). This annealing process is used to refine the grains and produce a more uniform and desirable grain size distribution (Callister 1997). Normalizing is typically performed on steels that have been coarsegrained as a result of being heated to high temperatures due to forging or welding, needlelike ferrite resulting in steel castings, or when the steel grains are oriented in the 
rolling direction (Totten and Howes 1997). The normalizing parameters include the heating rate, the austenitizing temperature, the holding time, and the cooling rate.

From this description, it appears that steel damaged and repaired using a maximum heating temperature of $1600^{\circ} \mathrm{F}$ is being normalized to produce much finer and uniform grain distribution. The literature indicates that the holding time at austenitizing temperatures may be calculated using the empirical equation below (Totten and Howes 1997).

$$
\mathrm{t}=60+\mathrm{D}
$$

In Equation (10), $\mathrm{t}$ is holding time in minutes and $\mathrm{D}$ is the maximum diameter of the work piece. In heat straightening, the maximum temperature is held for only a few seconds. Therefore, the two heating processes become rather unrelated. Normalizing is even more unrelated to heat straightening when maximum heating temperatures of either $1200^{\circ} \mathrm{F}$ or $1400^{\circ} \mathrm{F}$ are used for the repair as the Ac3 temperature is not exceeded.

\section{Tempering}

Martensite is formed when austenized steel is quenched at a fast rate (see Figure 6). Tempering is the process of heating martensitic steel to a temperature below the eutectoid temperature for a specified time. This tempering produces tempered martensite (Callister 1997). Tempered martensite may be nearly as hard and strong as martensite but with enhanced ductility and toughness.

Tempering is unrelated to heat straightening. In heat straightening, the austenized steel is not being cooled fast enough for the production of martensite. Martensite is the only microconstituent that can be enhanced by this type of heat treatment.

\section{Thermomechanical Treatments}

Thermomechanical treatments are processing treatments very similar to tempering or soft annealing, with the exception that they combine plastic deformation with the treatments. The purpose of a thermomechanical treatment is to enhance structural properties such as strength with ductility and/or toughness (Krauss 1980). For example, hot rolling is an example of a thermomechanical treatment. Three forms of thermomechanical treatments are: (1) low temperature thermomechanical treatment (LTMT); (2) high temperature thermomechanical treatment (HTMT); and (3) isoforming 
(ASM 1973). Figure 7 shows the three treatments schematically on an isothermal transformation diagram (ASM 1973).

- The Low Temperature Thermomechanical Treatment process (also known as ausforming) consists of lowering the temperature of the steel quickly below the Ac1 temperature so that no other micro-constituents form leaving the steel in a metasable austenite (MSA) phase. The steel in the MSA phase is deformed and then quenched rapidly to form martensite. This is followed by tempering to achieve the appropriate balance of structural properties.

- High Temperature Thermomechanical Treatment is the process where steel is deformed in the stable austenite phase above the Ac3 temperature. The steel is again quenched to martensite and tempered at appropriate temperatures.

- Isoforming is a process where the steel is deformed in the austenite phase at a temperature below the Ac1 temperature. However, in contrast to ausforming, the deformation continues until the phase transformation to ferrite/pearlite has completed. The steel is then slowly cooled to room temperature.

All three thermomechanical treatments involve plastic deformations at elevated temperatures, which occur during heat straightening. Low Temperature Thermomechanical Treatment and High Temperature Thermomechanical Treatment are both relatively different from heat straightening. Isoforming is similar to heat straightening at elevated temperatures with the exception of the holding time required for isoforming. The desired spheroidite microstructure was not seen in the microstructure investigations of damaged-repaired steels. 


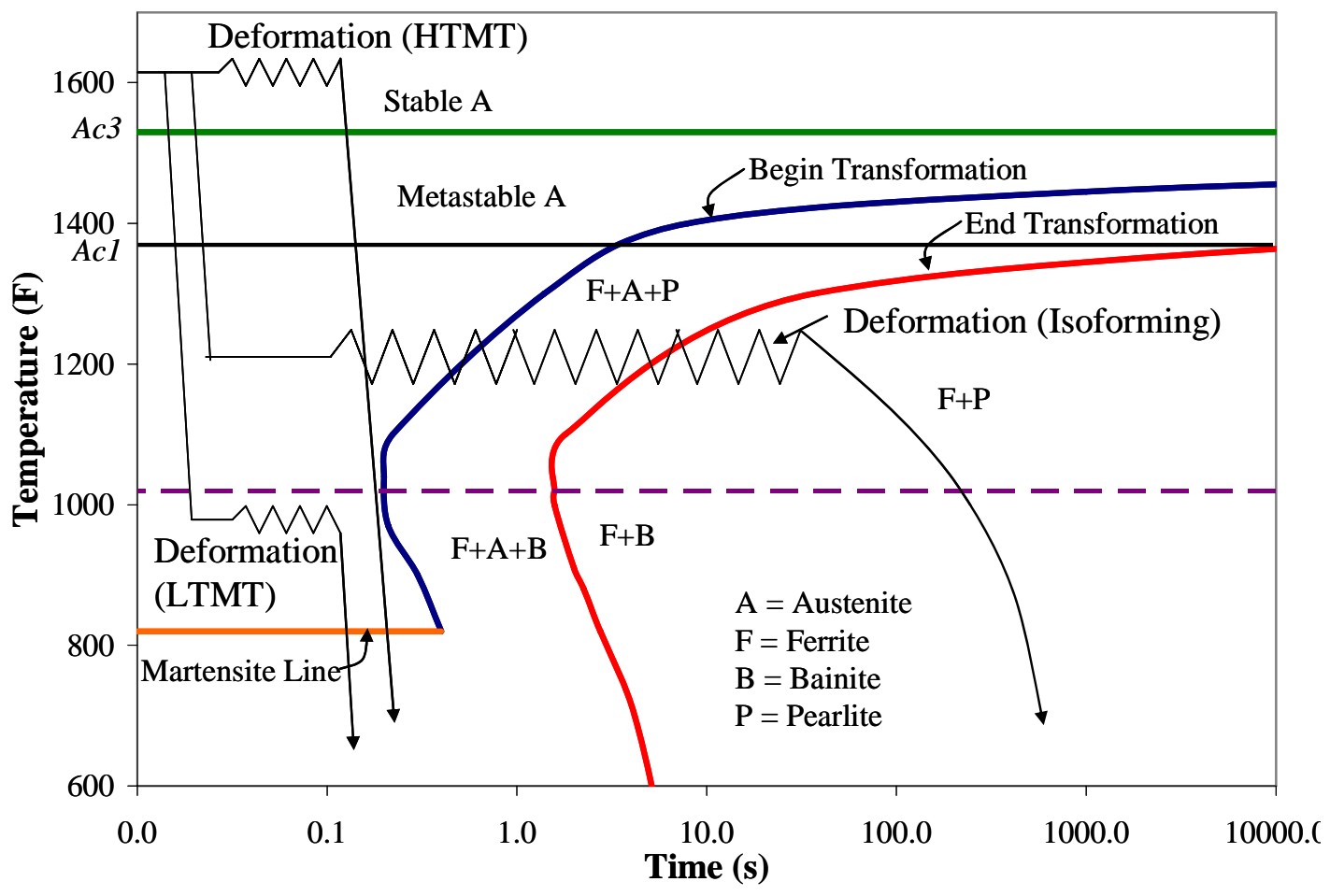

Figure 7. Thermomechanical treatments on an isothermal transformation diagram (Key to Metals 2004)

\subsection{RECOVERY, RECRYSTALLIZATION, AND GRAIN GROWTH}

A plastically deformed polycrystalline material exhibits possible changes in grain shape, strain hardening, and an increase in dislocation density (Callister 1997). Some fraction of the internal energy is stored in the metal as strain energy, which is associated with tensile, compressive, and shear zones around the newly created dislocations. These properties may be reverted to the prior cold-worked state by heat treatments such as annealing. The properties are reverted by two different processes that occur at elevated temperatures identified as recovery and recrystallization, which may be followed by grain growth.

\section{Recovery}

Recovery is the relief of some of the stored internal strain energy of a previously cold-worked metal by heat treatment. During recovery, the physical and mechanical properties of the cold worked steel begin to revert to the properties that existed prior to 
cold-working (ASM 1973). The rate of recovery is a thermally activated process that decreases with increasing time and decreasing temperature (Bryne 1965).

Early in the recovery process, some internal stresses are relieved and the number of dislocations slightly reduces. As recovery proceeds, dislocation interaction results in an increase of dislocation density as dislocation arrays are formed. These arrays constitute the walls of new cells (subgrains) of recovered steel and have lower energy configurations than the dislocation tangles, which made up the cold-worked metal (Totten and Howes 1997, Callister 1997). The internal strain energy is therefore relieved by a virtue of dislocation energy due to enhanced atomic diffusion at elevated temperatures. Recovery constructs the dislocations in a more stable arrangement forming small angle grain boundaries. This process is known as polygonization and is often a structural change that precedes recrystallization (Smith 2004).

The temperature of grain recovery $T_{G R}$ correlates with the recrystallization temperature $T_{R}$ and the melting temperature $T_{M}$ of the same material according to Equation (11) (Totten and Howes 1997). Assuming a melting temperature of $1400^{\circ} \mathrm{C}$ $\left(2550^{\circ} \mathrm{F}\right)$, the temperature of grain recovery and the recrystallization temperature is computed as $260^{\circ} \mathrm{C}\left(500^{\circ} \mathrm{F}\right)$ and $560^{\circ} \mathrm{C}\left(1040^{\circ} \mathrm{F}\right)$, respectively, using Equation (11).

$$
\mathrm{T}_{\mathrm{GR}}=\mathrm{T}_{\mathrm{R}}-300=0.4 \mathrm{~T}_{\mathrm{M}}-300\left[{ }^{\circ} \mathrm{C}\right]
$$

During heat treatment, it is difficult to draw a clear division between recovery and recrystallization as the two processes often overlap. Typically, only a slight decrease in the strength and hardness can be detected during recovery. Usually, the restoration of mechanical properties to annealed values is one-fifth achieved during recovery (Bryne 1963).

Grain recovery is likely to govern the micro-structural changes during heat straightening although the appropriate holding time for the grain recovery of steel was not found in the literature. The annealing of a cold-worked state produced by plastic deformation is quite complicated, since many types of point defects as well as dislocations can be present simultaneously and may interact during annealing. Probably the main issue in studying the annealing of plastically deformed steel is the differentiation between effects due to dislocations and those due to point defections. 
Research has shown that some dislocations are rearranged during recovery, as indicated by slight increases in average particle size prior to the temperature at which recrystallization produces a sharp hardness drop (Bryne 1963).

\section{Recrystallization}

Recrystallization refers to the formation of a new set of strain-free grains within a previously cold worked material (Callister 1997). In primary recrystallization, formation and growth occur in a deformed matrix of new grains, which are distortion-free and appreciably more perfect than the matrix after polygonization (Gorelik 1981). An annealing heat treatment such as process annealing is necessary for recrystallization to occur. During recrystallization, the restoration of mechanical and physical properties is completed, and there is a change in the preferred orientation before grain growth. There is a significant drop in tensile strength and hardness and a large increase in the ductility of steel.

Dynamic recrystallization is a process that combines elevated temperatures and plastic deformation. The process is therefore a form of hot working with subsequent recrystallization of deformed metal occurring. In contrast, the process of recrystallization that takes place after deformation is termed static recrystallization. In the course of hot deformation of a metal, strain hardening and softening are occurring in parallel (Gorelik 1981).

The most important factors that affect recrystallization in metals and alloys are; (1) amount of prior deformation, (2) temperature, (3) time, (4) initial grain size, and (5) composition of the metal or alloy (Smith 2004). The recrystallized volume in the material increases during annealing owing to two processes: the nucleation rate and the growth of the nuclei where the rate is described by two parameters known as the rate of nucleation, $N$, and the rate of growth, $G$. Both primarily depend on the amount of prior cold deformation. In hot deformation, they depend on both the amount and rate of deformation (Gorelik 1981).

Amount of deformation $\varepsilon$ : Beginning from a critical deformation, an increase in plastic strain causes $N$ and $G$ to increase and therefore the rate of recrystallization to grow. The size of the grains at the end of primary recrystallization is smaller after greater deformations. Coarse-grained structures can result after moderate or heavy deformations. 
However, this behavior is usually associated with secondary recrystallization. Secondary recrystallization requires long holding times and therefore is less likely to occur during heat straightening. In deformations below the critical strain $\varepsilon_{c r}$ value, only polygonization takes place during heating (Gorelik 1981). The values for the critical strain $\varepsilon_{c r}$ for steels are lacking in the literature. Elevated temperatures and slower heating shifts $\varepsilon_{c r}$ towards greater values.

Heating temperature: The kinetics of primary recrystallization is clearly temperature dependent. The recrystallization behavior of a particular metal alloy is sometimes specified in terms of a recrystallization temperature $T_{M}$ defined as the temperature at which recrystallization just reaches completion in 1 hour (Totten and Howes 1997). The recrystallization temperature of low carbon steel is approximately $1000^{\circ} \mathrm{F}$. A greater prior deformation and an increase in annealing time decrease the temperature for the start of recrystallization. The grains that form at the end of primary recrystallization at conventional heating rates become noticeably coarser with a further increase in temperature (Totten and Howes 1997).

Time of annealing: According to most researchers, the average rate of growth $G$, in contrast to $N$, is independent of annealing time until the growing recrystallization nuclei begin to collide. On the other hand, it has been established by direct observations that the rate of growth does vary with time. When deformations slightly exceed the critical value, the two processes of growth of initial grains and growth of recrystallization nuclei can occur in parallel. Therefore, the results of recrystallization and average grain size, based on annealing time at various strains are rather complicated (Gorelik 1981).

Initial grain size: A finer grain size increases the area of grain boundaries, which increases the probability of nucleation sites to form. Therefore, a finer initial grain size accelerates the process of primary recrystallization (Gorelik 1981).

Solute impurities : Solute impurities and alloying additions strongly influence the rate of primary recrystallization. For instance, a zone-refined iron deformed $10 \%$ undergoes polygonization at $250{ }^{\circ} \mathrm{C}$ and does not recrystallize. For an iron with $0.03 \% \mathrm{C}$, polygonization has no time to end and gives way to recrystallization.

Rate of Heating: Rapid heating to the recrystallization temperature prevents full recovery prior to recrystallization and causes a large driving force for recrystallization to 
remain. In addition, with rapid heating, higher temperatures are reached before recrystallization has time to begin, which facilitates nucleation of new grains (Gorelik 1981). Therefore, the higher the heating rate, the higher the recrystallization temperature (Totten and Howes 1997). Although critical heating rates could not be found from the literature, it is assumed that the rate of heating when heat straightening is not beneficial for recrystallization.

\section{Grain Growth}

After recrystallization is complete, the strain free grains will continue to grow if the steel specimen is left at elevated temperatures. Grain growth is referred to as the increase in average grain size of a polycrystalline material. Grain growth generally follows recovery and recrystallization. It occurs by the migration of grain boundaries. Not all grains can enlarge. Therefore, larger grains grow at the expense of smaller grains (Callister 1997). Extended annealing at a high temperature can cause a few grains to grow to a very large size, which is known as secondary recrystallization or abnormal grain growth (ASM 1973). After reviewing the literature on recrystallization, it appears that long holding periods would be required for the full process of recrystallization.

\subsection{SUMMARY}

A summary of the relative steel heat treatments currently used to enhance the physical and structural properties was presented. The review of these heat treatments indicated that process annealing is relatively similar to heat straightening when applying a maximum temperature of $1200^{\circ} \mathrm{F}$. Process annealing is applied to recover the internal strain energy and may be accompanied by recrystallization. The problem in this comparison is the holding time required to achieve the desired affect. The literature indicated holding times from one to forty-eight hours. However, the literature does not discuss the effects of shorter holding times with the exception of the statement that “annealing temperature decreases with longer holding times”.

Normalizing annealing uses higher temperatures followed by moderate cooling in air. This is similar to heat straightening when overheated temperatures (greater than $1200^{\circ} \mathrm{F}$ ) are used. Again, the problem in this comparison is the holding time required for 
the two processes. When heat straightening, temperatures exceeding the eutectoid temperature will only exist for a matter of seconds as opposed to hours, which is generally required for normalizing.

Other heat treatments do not appear to correlate to heat straightening. The possible formation of other micro-constituents due to rapid cooling was also discussed. These alternate micro-constituents include martensite and bainite, which are harder, stronger, and more brittle than pearlite. The literature revealed that an extremely fast cooling period would be required for the formation of martensite or bainite. Experimental investigations have indicated that the formation of martensite or bainite is not an issue when heat straightening.

This chapter also discussed the structure of plastically deformed steel. The defect seen in damaged steel microstructures is the formation of slip lines within the grains. The processes that occur in damaged and heated steels include recovery, recrystallization, and grain growth. Relatively low temperatures and holding times are required for recovery. Therefore, it is very likely that this process is occurring upon heat straightening. The resulting microstructures (in earlier research) indicate that recrystallization also occurs when heat straightening.

The issue again arises as to whether a heat-straightened member has the required holding time for recrystallization to complete. The literature shows that the temperature required for recrystallization in low carbon and high-strength low alloy steels is approximately $1000^{\circ} \mathrm{F}$ and should be held for 1 hour to complete. However, recovery and recrystallization begins immediately as the steel is heated. The recrystallization temperature decreases with increasing strain and longer holding periods. The influence of shorter holding periods and the aid of an external restraining stress could not be fully interpreted from the literature. An important finding from this review is that recrystallization is greatly dependent on the amount of prior deformation. A higher dislocation density increases the amount of area available for nucleation to proceed and decreases the recrystallization temperature. A specimen damaged to a higher strain has more area for nucleation sites to grow and is also subjected to more heating cycles.

Experimental results (Kowalkowski 2005) indicate that a more fine-grained and uniform microstructure evolves when using overheated temperatures of $1400^{\circ} \mathrm{F}$ or 
$1600^{\circ} \mathrm{F}$ during heat straightening as opposed to the recommended limit of $1200^{\circ} \mathrm{F}$. Upon heating, proeutecoid ferrite and pearlite grains transform into austenite grains, which eliminates the slip planes. The restraining stress decreases prior to cooling below the Ac1 temperature. Therefore, the initial damage strain and the restraining stress do not have a significant effect on the results. The grain sizes of all overheated specimens were lower than the undamaged grain size. Therefore, the strength and fracture toughness of the steel were substantially higher. It appears that using overheated temperatures allows for full recrystallization of the grains to occur. 


\section{Chapter 3 Survey of Heat Straightening}

\subsection{COMPANY LISTS}

The following three companies were surveyed to determine specific details of their heat straightening techniques, equipment, and capability of implementing heat treatment in the field. These three companies were selected because they have performed heat straightening for the state of Indiana.

(1) Flame On, Inc.

4415 Tom Marks Rd.

Snohomish, WA 98290

1-(425)-397-7039

General: info@flameoninc.com

Darryl Thomas: d.thomas@flameoninc.com

www.flameoninc.com

(2) National Bridge Company

4556 Arrowhead Rd.

Okemos, MI 48864

1-(517)-347-6167

$1-(517)-202-4772$

dgarijo@nationalbridge.com

http://www.nationalbridge.com/

(3) International Straightening, Inc.

6514 Island Dr.

Bismarck, ND 58504

1-(701)-223-5972 or

$1-(701)-223-6043$

info@steelstraightening.com

www.steelstraightening.com

\subsection{SURVEY FORM SUBMITTED TO COMPANIES}

PART I

1) Do you always use Oxygen-Fuel torches for heat straightening?
a) Yes
b) No
c) Write-in what you use

2) What fuel do you use for heat straightening?

a) Propylene

b) Acetylene 
c) Other please specify,

3) What is the pressure in the oxygen and fuel lines during heat straightening?

a) _ Oxygen, and Fuel

b) Don't know

c) Call person to find out.

4) What temperature measuring devices do you use to measure the steel temperature during heat straightening?
a) Visual color of steel
b) Temperature indicating crayons
c) Non-contact optical temperature indicating device
d) None
e) (write-in)

5) What temperature limit do you follow for heat straightening?
a) (write in for mild steel)

6) Does the above temperature limit ever get violated at the site?
a) Yes
b) No, never.
c) Sometimes when the job is done in a hurry

7) What is the depth and angle of Vee heat you typically use:
a) Full depth with vee angle of
b) Three quarter depth with Vee angle of
c) Half depth with Vee angle of
d) Varies with the job and have used all three (comments

\section{Part II}

8) Is there a supervisor regulating the temperature, load ratio, etc. on the job?
a) Yes, sometimes
b) Yes, all the time
c) $\mathrm{No}$
d) Other. _

9) How long are these supervisors present at the site per day? Per job?
a) 30 minutes
b) 1 hour
c) All day
d) Other. _ Please specify duration 


\section{Part III}

10) What hydraulic equipment do you use for heat straightening?
a) 25 ton jack
b) 50 ton jack
c) Other. Please specify,
d) Don't know

11) What hydraulic pressure or force do you use during heat straightening?
a) e.g., psi for a psi rated jack
b) Depends on the damage. Average psi for a psi jack
c) Don't know

12) Do you adjust the pressure during heating?
a) Yes
b) No
c) Sometimes, why?

13) Where do you apply the load?
a) Close to impact
b) Close to Vee heat location
c) Between the diaphragm

\section{Part IV}

14) Do you have an electrical power generator on your truck?
a) Yes
b) No
c) Maybe rented, type@ @ per day

15) How much power can your generator produce?
a) $25 \mathrm{~kW}$ or less
b) $25-50 \mathrm{~kW}$
c) $50-100 \mathrm{~kW}$
d) $100 \mathrm{~kW}$ or more
e) (write-in)

16) Can you rent a reasonable size $(25 \mathrm{~kW})$ electrical generator and bring it to the site if needed?
a) Yes
b) No
c) Maybe if the cost is less than \$ per day. 


\subsection{SURVEY RESULTS}

The first two of the three companies listed in Section 3.1 responded to the survey questionnaires. The third company (International Straightening Inc.) refused to respond to survey. Their proprietor (Mr. Holt) indicated that he did not wish to participate in the research study. The survey results from the first two companies are summarized below.

\section{PART I}

1) Do you always use Oxygen-Fuel torches for heat straightening? $100 \%$ (both companies) answered - YES

2) What fuel do you use for heat straightening?

$100 \%$-Propylene $50 \%$ (one of the two companies) - also uses Acetylene

3) What are the pressures and flow rates in the oxygen and fuel lines during heat straightening?

$50 \%-80$ psi Oxygen, and 25 psi Fuel

$50 \%$ - Varies based on the job

4) What temperature measuring devices do you use to measure the steel temperature during heat straightening?

$100 \%$ - Visual color of steel and temperature indicating crayons used by practitioners

$50 \%$-Non-contact optical temperature indicating device by inspectors

5) What temperature limit do you follow for heat straightening? 100\%-1200 degrees Fahrenheit

6) Does the above temperature limit ever get violated at the site? $100 \%$-No, never

7) What is the depth and angle of Vee heat you typically use?

$100 \%$-Varies with the job and have used all three 


\section{PART II}

8) Is there a supervisor regulating the temperature, load ratio, etc. on the job? $100 \%$ - Yes, from within the company

9) How long are these supervisors present at the site per day? Per job? $100 \%$ - For the entire job

\section{PART III}

10) What hydraulic equipment do you use for heat straightening?

$50 \%$ - 50 ton jack

$50 \%-10$ ton jack

11) What hydraulic pressure or force do you use during heat straightening?

$100 \%$ - Depends on the damage

$50 \%$ - Average of 6000 psi for a 10,000 psi jack

12) Do you adjust the pressure during heating?

$50 \%-\mathrm{No}$

$50 \%$-Sometimes, when the jack is going to fall out

13) Where do you apply the load?

$100 \%$-Close to impact

\section{PART IV}

14) Do you have an electrical power generator on your truck?

$$
100 \% \text {-Yes }
$$

15) How much power can your generator produce?

$100 \%-25 \mathrm{~kW}$ or less (8kw)

16) Can you rent a reasonable size $(25 \mathrm{~kW})$ electrical generator and bring it to the site if needed?

$100 \%$-Yes 


\section{Chapter 4: Heat Treatment Feasibility Analysis}

\section{(1) Identifying heating and control equipment required for conducting heat treatment in the field.}

In order to repair a damaged steel bridge girder to its proper shape and maintain the steel's material properties, it is suggested that the steel be heat straightened and then heat treated through two separate and distinct processes. The processes can be separated in this manner to minimize working time in the field, to reduce overall costs, and to maximize the steel shape integrity and properties.

The heat straightening practitioners can begin the repair process as usual. This would include following all industry accepted regulations, techniques, and specifications. These will include but are not limited to: following the maximum heating temperature (steel surface temperature can be measured by any accurate measuring device or by visual inspection), using proper heating patterns to create the desired thermo-plastic displacements, etc. A complete discussion of the heat straightening process is found in the heat straightening literature review of this report. After the heat straightening process has been performed, the steel bridge girder should appear to be in a straight and prismatic in shape (within tolerances), i.e., similar to state before the steel bridge girder was damaged by impact.

A supplemental heat treatment repair process can then be performed to improve the damaged steel material properties and bring them closer to their undamaged values. The combination of the heat straightening and treatment repair processes will restore both the shape and the structural properties of the steel and therefore will be more beneficial then heat straightening alone where there is only shape restoration and inadequate repair of the steel microstructure.

The supplemental heat treatment can be provided using the same oxygen-fuel torches as the heat straightening repair process. However, the time duration for the heat treatment repair process is too long for manual management of the oxygen-fuel torches. As an alternative, ceramic fiber radiant heaters can be considered for applying the supplemental heat treatment. The heat treatment can be provided using (a) flat panel ceramic fiber radiant heaters, (b) temperature and power controllers to regulate the time- 
temperature history imposed by the radiant heaters, and (c) electrical generator to supply the on-site power for the heater.

There are several precautions that must be set in place to ensure the safety of the heat treatment operation. Only one ceramic fiber heater should be used per span on a given heat treatment job. The heating should be limited to portions of the steel girder that have been heat straightened, though non-heat straightened areas can also be heat treated without negative consequences. After heat treatment of one portion is completed, the heating setup should be moved to an adjacent heat straightened portion, and so on, until all the heat straightened portions of the girders have been treated. The heat treatment process should be used in this manner (rather than heating the entire straightened area at one time) because the heated portions of the steel girder become much weaker during the treatment process.

\section{(2) Capital expenses for purchasing equipment, the extent of control available, and the power requirements at the site.}

This Section will address some important questions regarding the implementation of heat treatment in the field. These include: (a) the capital expenses for purchasing the equipment, (b) the degree of control available, and (c) the power requirements at the site. The discussion of the capital expenses will be limited to the equipment and tools required for the heat treatment repair because these will be the future costs that the heat straightening company will incur. The extent of control available section will discuss the precision of the temperature control and the ability to control where the heat energy is placed on the steel bridge girder. The power requirements at the site are derived from the power requirements of the heating devices and the practical availability of electrical power at the heat straightening repair time.

In order to decrease the time in the field performing the heat treatment process, it is suggested that a flat panel ceramic fiber heater be used that is large enough to reduce the amount of heat treatments over the length of the beam. It must also not be too large that adequate internal restraint is not maintained. The suggested heater size is 40 inches long, 16 inches wide, and 2 inches thick. This unit will weigh under 20 pounds and will provide $11.5 \mathrm{~kW}$ through a parallel series of a 240 volt connection. The power 
requirement for the ceramic fiber heaters is within the achievable range for heat straightening practitioners (see survey results to question numbers 15 and 16). The survey results indicate that the heat straightening practitioners can easily provide an on-site generator to supply the electric power for the heaters. In addition to the ceramic fiber heater, a temperature control device as well as a power switching device will also be required. All this equipment has been quoted by Thermtech Systems, Inc. as follows. The flat panel ceramic fiber heater has been quoted at $\$ 907.12$, the temperature control device at $\$ 616.00$. and the power switching device at $\$ 100.80$. The purchase order for this setup will cost $\$ 1623.92$ and will serve as a fixed cost. The only future cost will be to supply the energy to run the heater.

The heat energy from the flat panel ceramic fiber heater will not remain localized at the point of heating similar to the heat from an oxygen-fuel heat straightening torch. While using a flat panel ceramic fiber heater the heat will transfer from the section of the member being heated to adjacent portions through heat conduction. This heat transfer is due to the longer durations required to adequate heat treat the material with a flat panel ceramic fiber heater.

\section{(3) Quality control and techniques for inspecting the heat treatment performed.}

In order to properly conduct heat treatment of the steel section, the steel must maintain an elevated temperature for an extended period of time. The flat panel ceramic fiber heater must maintain the appropriate temperature as well as maintain the appropriate distance (2"-4") between the surface of the steel and the surface of the heater. Maintaining the steel temperature at a constant level for at least one hour can ensure that the steel has undergone the heat treatment process adequately. In order to understand the effectiveness of the heat treatment at a quantitative level, research should be conducted to evaluate the effects of heat straightening followed by heat treatment on the microconstituents, the microstructure, and the material properties of the steel.

\section{(4) Examining the need for bridge lane closures or traffic redirection while heat treatment is being performed.}


During the heat treatment process, there may be a need to close the traffic on the bridge, but it will probably not be necessary to close traffic under the bridge. The traffic on the bridge will need to be closed because it causes an increased live loading on the members being heat treated. This live loading creates additional serviceability concerns which need to be analyzed prior to performing the heat treatment process. During the process of heat treatment, the steel will be weaker and additional loading could certainly increase deflections. Due to the redundant nature of the steel bridge girder design, the traffic loading does not necessarily indicate problems. There is a possibility that some lanes can remain open due to the redundant nature of the bridge but further research and analysis must be completed to verify this.

\section{(5) Issues related to fracture and non-fracture critical bridges.}

Whenever fracture of the bridge is a concern extra precautions need to be made to reduce the bridges susceptibility to this failure mode. A member that is non-redundant is deemed as fracture critical because the fracture of this member during the heat straightening or heat treatment process will force a failure of the whole structure. In general, if the member satisfies the fracture critical criteria for heat straightening than it should also be acceptable for the same member to be heat treated.

\section{(6) Evaluating the reduced strength of the bridge during the heat treatment for rehabilitation.}

During the heat treatment process, a significant amount of heat energy will be transferred from the ceramic fiber heaters to the steel. The increase in temperature of the steel created by the introduction of heat to the material will cause the strength of the steel to weaken. Therefore, the potential for deflection of the steel bridge girder during heat

treatments needs to be analyzed and considered. In order to minimize deflections, only one ceramic fiber heater should be used on a given girder span, the ceramic fiber heater should be placed directly at the previously heat straightened portions of the steel. The heaters should be close to the steel surface to ensure efficient transfer of heat 


\section{(7) Anticipating the mechanical properties of the steel after rehabilitation.}

The heat treatment process will take approximately one hour per section of the steel bridge girder. Upon completion of the recovery, grain growth, and recrystallization of the steel material, the material properties will be increased significantly beyond that of heat straightening alone. It can be expected that the heat straightening and following heat treatment processes will lead to: (a) small changes in the elastic modulus and the ultimate stress of the steel, (b) slight increase in the steel yield stress and reduction in the ductility (percent elongation), and (c) fracture toughness values approximately equal or greater than the undamaged steel fracture toughness.

Additional research is recommended to verify the expected effects of heat straightening and treatment to the structural properties and fracture toughness mentioned here. 


\section{REFERENCES}

American Railway Engineering Association (1946). "Flame Shortening Eyebars to Equalize the Stress,” Bulletin No. 460.

ASTM (1999c). "Standard Test Methods and Definitions for Mechanical Testing of Steel Products,” A370-97a, West Conshohocken, PA.

Avent, R. R. and Mukai, D.J. (2001). "Engineered Heat straightening Repairs: A Case Study,” Journal of Bridge Engineering, Mar. /Apr., pp. 95 - 102.

Avent, R. R., Mukai, D.J. and Robinson, P.F. (2001). "Residual-Stresses in Heat Straightened Steel Members,” Journal of Materials in Civil Engineering, ASCE, Vol. 13, No. 1, Jan./Feb., pp. 18 - 25.

Avent, R. R., Mukai, D.J. and Robinson, P.F. (2000a). "Effect of Heat Straightening on Material Properties of Steel,” Journal of Materials in Civil Engineering, ASCE, Vol. 12, No. 3, August, pp. 188 - 195.

Avent, R. R., Mukai, D.J., Robinson, P.F. and Boudreaux, R.J. (2000b). "Heat Straightening Damaged Steel Plate Elements,” Journal of Structural Engineering, ASCE, Vol. 126, No. 7, July, pp. 747 - 754.

Avent, R.R. and Mukai D.J. (1998a). "Implementation of Heat straightening Repairs for Louisiana Bridges”, State Project Number 736-99-0680, Louisiana Transportation Research Center, Louisiana State University, Baton Rouge.

Avent, R. R., and Mukai D.J. (1998b). "Heat Straightening Repairs of Damaged Steel for Bridges”, FHWA Report, U.S. Dept. of Transportation, Federal Highway Administration, Washington, D.C.

Avent, R. R. and Brakke, B.L. (1996). “Anatomy of Steel Bridge Heat straightening Project” Transportation Research Record, No. 1561, TRB, National Research Council, Washington, D.C. pp. 26-36.

Avent, R. R. (1992a). “Designing Heat straightening Repairs.” Proceedings, National Steel Construction Conference, AISC, Las Vegas, Nev., June, pp. 21-23. 
Avent, R. R. (1992b). “Design Procedures for Heat straightening Repairs: An Engineering Guide,” FHWA/LA-92/252, Louisiana Transportation Research Center, Louisiana State University, Baton Rouge.

Avent, R. R., Robinson, P.F., Madan, A., and Shenoy, S. (1992). “Development of Engineering Design Procedures for Heat straightening Repair of Damaged Structural Steel in Bridges,” LTRC 251, Louisiana Transportation Research Center, Baton Rouge, LA.

Avent, R. R., Fadous, G.M., and Boudreaux, R. J. (1991). “Heat straightening of Damaged Structural Steel in Bridges,” Transportation Research Board, No. 1319 TRB, National Research Council, Washington, DC. Pp. 86-93.

Avent, R. R. and Fadous, G. M. (1989). “Heat straightening Prototype Damaged Bridge Girders,” Journal of Structural Engineering, ASCE, Vol. 115, No. 7, July.

Avent, R. R. and Fadous, G. M. (1988). "Heat straightening Techniques for Repair of Damaged Structural Steel in Bridges,” Final Report, Louisiana Transportation Research Center, Louisiana State University, Baton Rouge.

Avent, R. R. and Fadous, G. M. (1987). "Heat straightening Effects on the Behavior of Full-Scale Simulated Bridge Girders,” First Interim Report of Phase 2, Louisiana Transportation Research Center, Louisiana State University, Baton Rouge.

Avent, R. R. and Boudreaux, R. J. (1987). "Heat straightening Effects on the Behavior of Plates and Rolled Shapes,” Second Interim Report of Phase I, Louisiana Transportation Research Center, Louisiana State University, Baton Rouge.

Barsom J. M. and Rolfe, S. T. (1987). "Fracture \& Fatigue Control in Structures Applications of Fracture Mechanics”, $2^{\text {nd }}$ Edition, Prentice-Hall, Englewood Cliffs, New Jersey.

Blodgett, O. W., “Distortion...How Metal Properties Affect It,” Welding Engineer, February, 1972, pp. 40-46.

Boudreaux, R.J. (1987). “Heat straightening of Steel: Identifying the Important Parameters and Predicting Member Response,” MS Thesis, Louisiana State University, Baton Rouge. 
Brockenbrough, R.L. and Ives, K.D. (1970). "Experimental Stresses and Strains from Heat Curving,” Journal of the Structural Division, ASCE, Vol. 96, No. ST7, Proc. Paper 7400, July, pp. 1305-1331.

Brockenbrough, R.L. (1970). "Theoretical Stresses and Strains from Heat Curving," Journal of the Structural Division, ASCE, Vol. 96, No. ST7, Proc. Paper 7410, July, pp. 1421-1444.

deBejar, L. A., Robinson, P.F. and Avent, R.R. (1992a). "Risk Consistent Estimate of Heat straightening Application. I: Plates, “Journal of Structural Engineering, ASCE, 118(12), 3394-3409.

deBejar, L. A., Robinson, P.F. and Avent, R.R. (1992b). "Risk Consistent Estimate of Heat straightening Application. II: Beams, "Journal of Structural Engineering, ASCE, 118(12), 3440-3426.

Ditman, O. (1961). "Determination of Thermal Shrinkage in Structural Steel,” MS Thesis, University of Washington.

Fadous, G. M. (1987). "Heat straightening Effects on the Behavior of a Full-Scale Simulated Bridge Girder,” MS Thesis, Louisiana State University, Baton Rouge. FHWA (1998), "Heat straightening Repairs of Damaged Steel Bridges - A Technical Guide and Manual of Practice,” Report NO. FHWA-IF-99-004, Federal Highway Administration, Washington, D.C.

For Chin, W., “Linear Shrinkage of Steel,” MS Thesis, University of Washington, 1962. Harrison, H. L., “Straightening Structural Members in Place,” Welding Journal, Vol. 31, No. 5, May, 1952, Research Supplement, pp. 257s-262s.

Holt, J. E. (1955). “Flame Straightening: A Friend in Need,” Welding Engineer, Vol. 40, No. 10, October, pp. 44-46, No. 12, December, pp. 30-31.

Holt, J. E. (1938). “Contraction a Friend in Need,” Typed and Copyrighted.

Holt, R. E. (1977). “How to Control and Correct Warping,” Welding Design and Fabrication, June, pp. 98-102. 
Holt, R. E. (1971). “Primary Concepts in Flame Bending,” Welding Engineer, Vol. 56, No. 6, June, pp. 416-424.

Holt, R. E. (1965). “Flame Straightening Basics,” Welding Engineer, Vol. 50, No. 9, September, pp. 49-53.

Horton, D. L. (1973). “Heat Curved Mild Steel Wide Flange Sections: An Experimental and Theoretical Analysis," MS Thesis, University of Washington.

Moberg, K. L. (1979). “Damage Assessment and Contraction Straightening of Steel Structures,” MS Thesis, University of Washington.

Nichols, J. I. and Weerth, D. E. (1972). "Investigation of Triangular Heats Applied to Mild Steel Plates,” Engineering Journal, AISC, October, pp. 137-141.

Pattee, H. E., Evans, R. M. and Monroe, R. E. (1970). "Effect of Flame and Mechanical Straightening on Material Properties of Weldments," Summary Report on Ship Structure Committee on Project SR-185, Straightening Distorted Weldments.

Pattee, H. E., Evans, R. M. and Monroe, R. E. (1969). "Flame Straightening and its Effect on Base Metal Properties," Summary Report to Ship Structure Committee concerning the first phase of Project SR-185, Straightening Distorted Weldments, Battelle Memorial Institute, Columbus, Ohio, August.

Putherickal, J. (1992). “Effects of Heat Straightening Structural Steel”, Final Report for MLR-91-3, Iowa Dept. of Transportation, Ames, Iowa.

Robinson, P.F. (1991). "Behavioral characteristics of damaged steel repaired by heat straightening,” PhD thesis, Louisiana State Univ., Baton Rouge, La.

Roeder, C. W. (1986). “Experimental Study of Heat Induced Deformation,” Journal of Structural Engineering, ASCE, Vol. 112, No. 10, October, pp. 2247-2262.

Roeder, C. W. (1985). “Use of Thermal Stress for Seismic Damage Repair,” Final Report on NSF Grant CEE-82-05260, University of Washington, Seattle, October.

Rothman, R. L. (1973). "Flame Straightening Quenched and Tempered Steels in Ship Construction,” Ship Structures Committee, Report No. 235. 
Till, R. D. (1996). "Effect of Elevated Temperature on Fracture Critical Steel Members,” MDOT Research Report No. R-1344, Materials and Technology Division, Michigan Department of Transportation, pp. $1-17$.

Shanafelt, G. O. and Horn, W. G. (1984). “Guidelines for Evaluation and Repair of Damaged Steel Bridge Members,” NCHRP Report No. 271, Transportation Research Board, National Research Council, Washington, DC, June.

Weerth, D. E. (1971). “Theoretical and Experimental Analysis of Heat Curved Mild Steel,” MS Thesis, University of Washington. 